Prepared in cooperation with the Chicago District of the U.S. Army Corps of Engineers

\title{
Evaluation of the Potential for Hysteresis in Index-Velocity Ratings for the Chicago Sanitary and Ship Canal near Lemont, Illinois
}

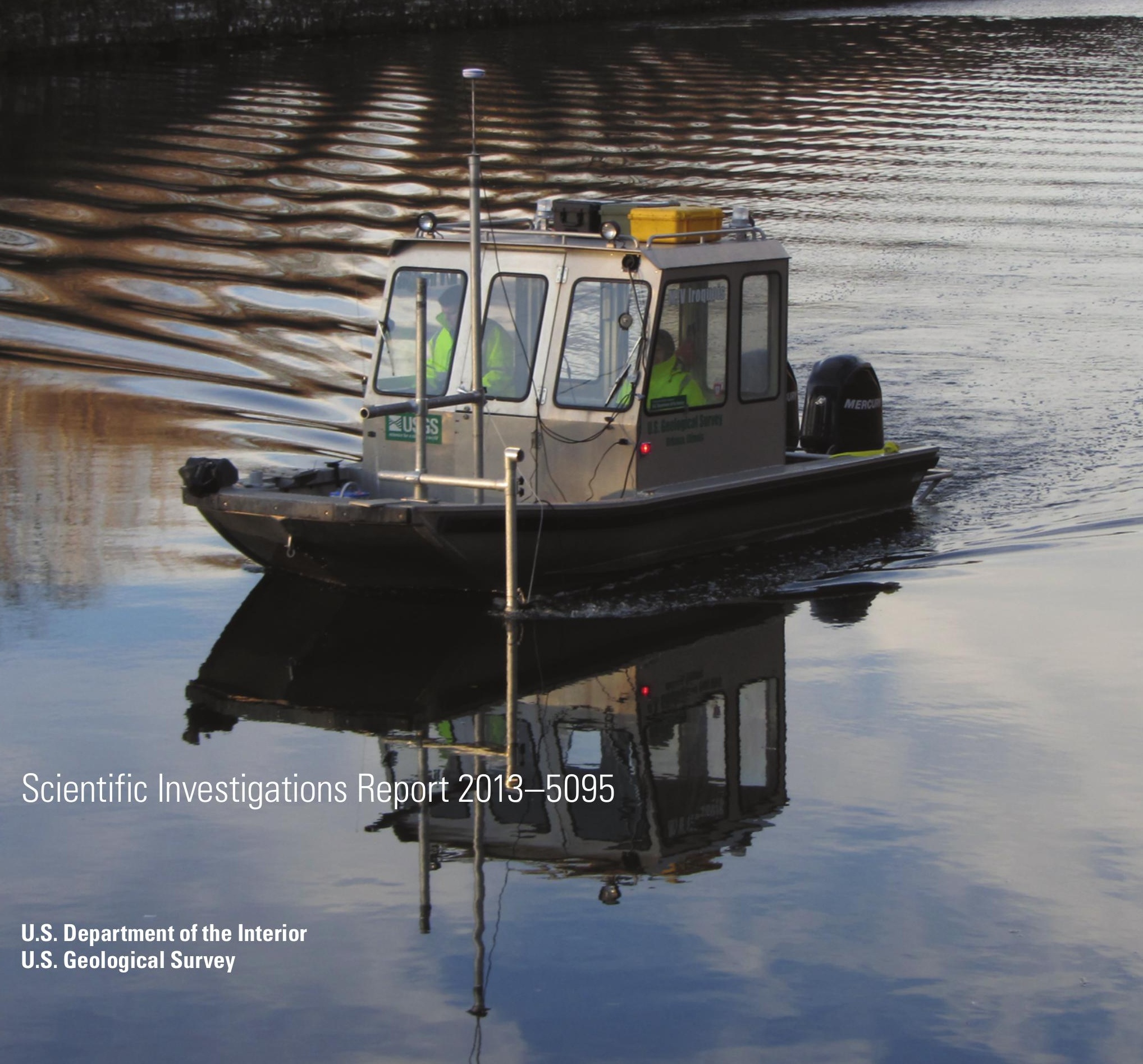


Cover photo. Photograph of a survey boat making measurements in the Chicago Sanitary and Ship Canal near Lemont, Illinois. (Photo by K. Johnson, U.S. Geological Survey.) 


\section{Evaluation of the Potential for Hysteresis in Index-Velocity Ratings for the Chicago Sanitary and Ship Canal near Lemont, Illinois}

By P. Ryan Jackson, Sumit Sinha, Som Dutta, Kevin K. Johnson, James J. Duncker, and Marcelo H. Garcia

Prepared in cooperation with the Chicago District of the U.S. Army Corps of Engineers

Scientific Investigations Report 2013-5095 


\title{
U.S. Department of the Interior SALLY JEWELL, Secretary
}

\section{U.S. Geological Survey Suzette M. Kimball, Acting Director}

\author{
U.S. Geological Survey, Reston, Virginia: 2013
}

For more information on the USGS - the Federal source for science about the Earth, its natural and living resources, natural hazards, and the environment, visit http://www.usgs.gov or call 1-888-ASK-USGS.

For an overview of USGS information products, including maps, imagery, and publications, visit http://www.usgs.gov/pubprod

To order this and other USGS information products, visit http://store.usgs.gov

Any use of trade, firm, or product names is for descriptive purposes only and does not imply endorsement by the U.S. Government.

Although this information product, for the most part, is in the public domain, it also may contain copyrighted materials as noted in the text. Permission to reproduce copyrighted items must be secured from the copyright owner.

Suggested citation:

Jackson, P.R.; Sinha, Sumit; Dutta, Som; Johnson, K.K.; Duncker, J.J.; and Garcia, M.H., 2013, Evaluation of the potential for hysteresis in index-velocity ratings for the Chicago Sanitary and Ship Canal near Lemont, Illinois: U.S. Geological Survey Scientific Investigations Report 2013-5095, 33 p., http://pubs.usgs.gov/sir/2013/5095/ 


\section{Contents}

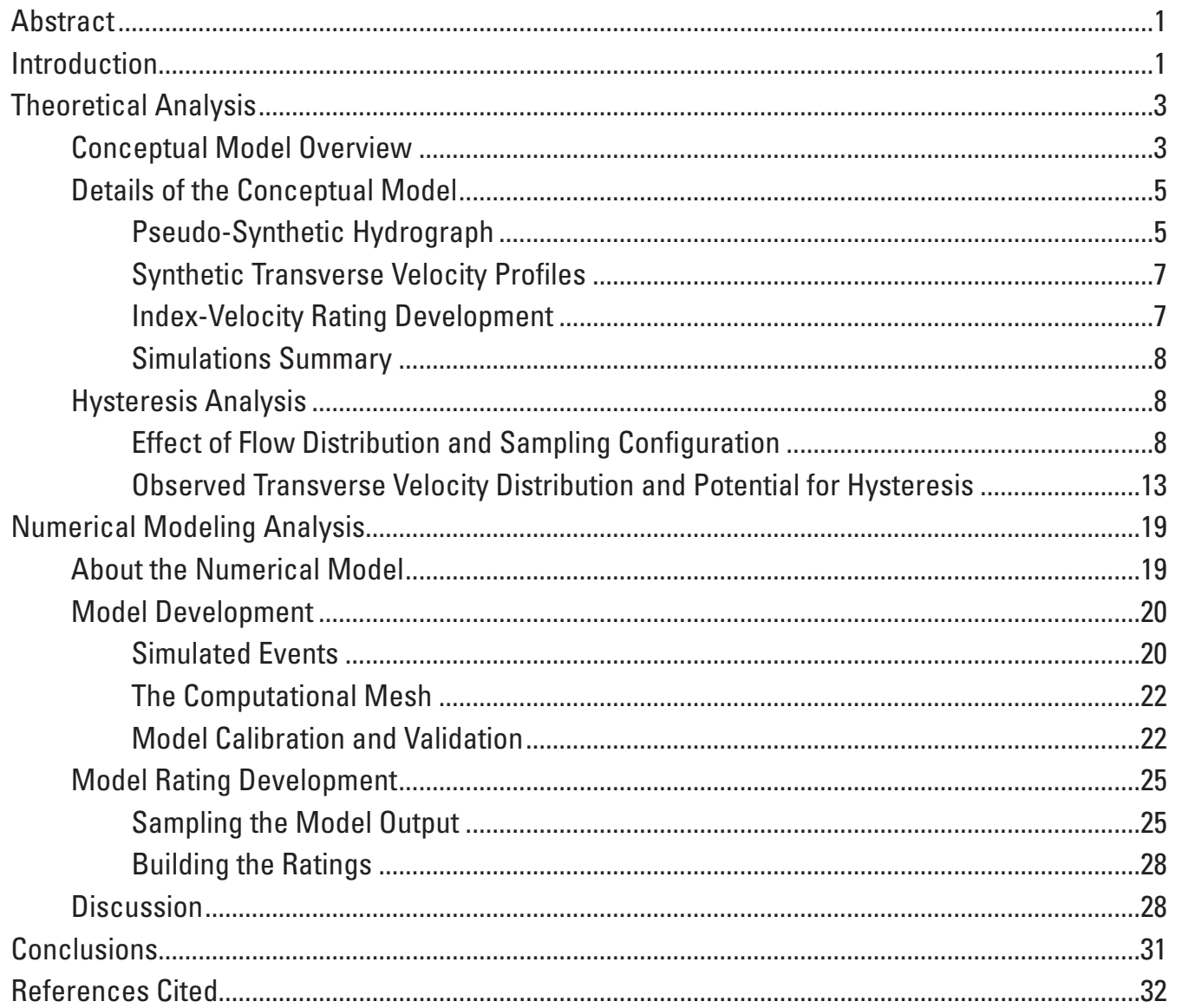

\section{Figures}

1. Map of the Chicago Area Waterway System (CAWS) showing the Chicago Sanitary and Ship Canal (CSSC), Calumet Sag Channel, North Branch Chicago River, Little Calumet River, Grand Calumet River, and the other waterways in and near Chicago, Illinois. Locations of USGS streamgages and the extent of the model domain also are shown for reference

2. Schematic showing the instrument configurations and the channel bathymetry at the U.S. Geological Survey streamgage on the Chicago Sanitary and Ship Canal near Lemont, Illinois (05536890)...

3. Workflow schematic for the conceptual model .............................................................

4. Compilation plot for a single simulation using a symmetric flow distribution and the sampling configuration for the horizontal acoustic Doppler current profiler.

5. Index-velocity rating curves for six simulations using the H-ADCP configuration and beta density function coefficients as shown in each figure. 
6. Six-panel plot showing the sensitivity of the horizontal acoustic Doppler current profiler (H-ADCP) sampling configuration to various distributions of the transverse velocity profile over a typical high-flow event.

7. Six-panel plot showing the sensitivity of the acoustic velocity meter (AVM) sampling configuration to various distributions of the transverse velocity profile over a typical high-flow event.

8. Six-panel plot showing the sensitivity of a single 15 -foot, centered-cell sampling configuration to various distributions of the transverse velocity profile over a typical high-flow event.

9. Six-panel plot showing the sensitivity of a five-cell, right-half with blanking zone sampling configuration to various distributions of the transverse velocity profile over a typical high-flow event.

10. Index-velocity rating curves for two cases with highly skewed flow and a five-cell, right-half with blanking zone sampling configuration.

11. Distribution of $\alpha$ and $\beta$ for observations from 102 high-flow events in the Chicago Sanitary and Ship Canal near Lemont, Illinois

12. Histograms of $\alpha$ and $\beta$ for observations from 102 high-flow events in the Chicago Sanitary and Ship Canal near Lemont, Illinois

13. Compilation plot for the observed median flow distribution and the sampling configuration for the horizontal acoustic Doppler current profiler 18

14. Comparison of the field-derived index-velocity rating for the horizontal acoustic Doppler current profiler (H-ADCP) in Chicago Sanitary and Ship Canal (CSSC) near Lemont, Illinois, to the conceptual-model rating curve developed by using median values of the beta distribution coefficients from observed velocity profiles

15. Synthetic hydrographs for the Chicago Sanitary and Ship Canal (CSSC) and Cal-Sag Channel upstream of Sag Junction and measured discharge in the CSSC at Lemont and free surface elevation in the CSSC at Romeoville Road corresponding to case 1 and case 2 .

16. Measured hydrographs for the Chicago Sanitary and Ship Canal (CSSC) and Cal-Sag Channel and water-surface elevation in the CSSC at Romeoville Road corresponding to event 1 , event 2, event 3 , and event 4

17. Top view and three-dimensional view of the computational mesh for the modeled domain

18. Comparison between simulated and observed water-surface elevation at the USGS streamgage on the Chicago Sanitary and Ship Canal near Lemont, Illinois (05536890), corresponding to all simulated cases and observed events.

19. Comparison between simulated and observed discharge at the USGS streamgage on the Chicago Sanitary and Ship Canal near Lemont, Illinois (05536890), corresponding to all synthetic cases and measured events

20. Model-derived index-velocity rating curves corresponding to the acoustic velocity meter (AVM) sensor configuration for all simulated cases and events

21. Model-derived index-velocity rating curves corresponding to the horizontal acoustic Doppler current profiler (H-ADCP) sensor configuration for all simulated cases and events...... 


\section{Tables}

1. Annual mean and peak discharge measured at USGS streamgage on the Chicago Sanitary and Ship Canal near Lemont, Illinois (05536890), water years 2006 to 2012

2. Simulated high-flow events in the Chicago Sanitary and Ship Canal near Lemont, Illinois.

3. Error between predicted and observed velocities in the nine cells of the horizontal acoustic Doppler current profiler in the Chicago Sanitary and Ship Canal near Lemont, Illinois. Median values of the root mean squared error (RMSE) are reported independently for the two stage-discharge relation regimes.. 


\section{Conversion Factors}

\begin{tabular}{lcl}
\hline \multicolumn{1}{c}{ Multiply } & By & \multicolumn{1}{c}{ To obtain } \\
\hline foot $(\mathrm{ft})$ & Length & meter $(\mathrm{m})$ \\
meter $(\mathrm{m})$ & 0.3048 & foot $(\mathrm{ft})$ \\
mile $(\mathrm{mi})$ & 3.281 & kilometer $(\mathrm{km})$ \\
\hline & 1.609 & \\
\hline square foot $\left(\mathrm{ft}^{2}\right)$ & Area & square meter $\left(\mathrm{m}^{2}\right)$ \\
square meter $\left(\mathrm{m}^{2}\right)$ & 0.09290 & square foot $\left(\mathrm{ft}^{2}\right)$ \\
\hline & 10.76 & \\
\hline foot per second $(\mathrm{ft} / \mathrm{s})$ & Velocity & meter per second $(\mathrm{m} / \mathrm{s})$ \\
\hline & 0.3048 & cubic meter $\mathrm{per} \mathrm{second}\left(\mathrm{m}^{3} / \mathrm{s}\right)$ \\
\hline cubic foot per second $\left(\mathrm{ft}^{3} / \mathrm{s}\right)$ & Flow rate & \\
\hline
\end{tabular}

Vertical coordinate information is referenced to the North American Vertical Datum of 1988 (NAVD 88) and the National Geodetic Vertical Datum of 1929 (NGVD 29).

Horizontal coordinate information is referenced to the North American Datum of 1983 (NAD 83).

\section{Acknowledgments}

The authors wish to thank Jim Best and Dan Parsons for the use of the multibeam bathymetry used in the model. A special thanks goes to the USGS hydrologists who improved this report through their helpful reviews and the USGS personnel who assisted with data collection. 


\title{
Evaluation of the Potential for Hysteresis in Index-Velocity Ratings for the Chicago Sanitary and Ship Canal near Lemont, Illinois
}

\author{
By P. Ryan Jackson', Sumit Sinha², Som Dutta ${ }^{2}$, Kevin K. Johnson', James J. Duncker', \\ and Marcelo H. Garcia²
}

\section{Abstract}

The U.S. Geological Survey (USGS) is responsible for monitoring flows in the Chicago Sanitary and Ship Canal (CSSC) near Lemont, Illinois, as a part of the Lake Michigan Diversion Accounting overseen by the U.S. Army Corps of Engineers, Chicago District. Lake Michigan Diversion Accounting is mandated by a U.S. Supreme Court decree in order to monitor, and limit, the State of Illinois' annual diversion of Great Lakes water through the manmade CSSC. Every 5 years, a technical review committee consisting of practicing engineers and academics reviews USGS streamgaging practices in the CSSC near Lemont, Illinois. The sixth technical review committee expressed concern that the index-velocity rating - the method used to estimate mean cross-sectional velocity from a measured index velocity - may be subject to hysteresis at this site because of the unique, unsteady hydraulics of the canal. Hysteresis in index-velocity ratings can occur at sites where the flow distribution in the channel varies significantly between the rising and falling limbs of the hydrograph for the same discharge. Presently, hysteresis in index-velocity ratings has been documented only in tidally affected sites. This report investigates whether hysteresis can occur at this nontidal site, and the conditions under which it is likely to occur, by using both a theoretical approach and a three-dimensional hydrodynamic model. The theoretical analysis investigated the conditions required for hysteresis in the index-velocity rating, and the modeling analysis focused on the effect of the timing of the inflows from the CSSC and the Cal-Sag Channel on the potential for hysteresis and whether highly resolved simulations of actual high-flow events show any evidence of hysteresis.

Based on both a theoretical analysis using observed historical data and an analysis using a three-dimensional hydrodynamic model, there is no conclusive evidence for the existence of hysteresis in the index-velocity rating at

${ }^{1}$ U.S. Geological Survey.

${ }^{2}$ University of Illinois at Urbana-Champaign. the USGS streamgage on the CSSC near Lemont, Illinois. Although the theoretical analysis indicated the possibility of hysteresis at this site, the hydrodynamic conditions required to generate hysteresis are not present at this site based on historical data. Ongoing streamgaging practices at this site will use the information in this report and include periodic assessment of the index-velocity rating for any signs of hysteresis that might result from future changes to the operation of this manmade canal.

\section{Introduction}

The construction of the Chicago Sanitary and Ship Canal (CSSC) in the late 1800s allowed the reversal of the Chicago River in 1900, enabling Chicago to send diluted wastewater effluent downstream to the Mississippi River system and away from the city's freshwater source, Lake Michigan. Illinois' use of Lake Michigan water for consumption and dilution of wastewater resulted in a net diversion of water from the Great Lakes Basin, leading to a U.S. Supreme Court decree limiting Illinois' diversion of Great Lakes water. This decree established the need for diversion accounting and continuous measurement of the discharge of water out of Lake Michigan through the CSSC. To ensure that the best engineering practices and technology are being used in diversion accounting, a technical review committee consisting of practicing engineers and academics is convened every 5 years to review U.S. Geological Survey (USGS) streamgaging practices on the CSSC near Lemont, Illinois (Ill.) (station 05536890). With locks and control works throughout the Chicago Area Waterway System (CAWS) and significant influences from industry, the CSSC is a highly regulated, unnatural waterway with continuous perturbations that propagate from the lakefront to Lockport Lock and Dam just upstream of the confluence with the Des Plaines River (fig. 1). Continuous and accurate measurement of discharge in the CSSC requires innovative technology, measurement redundancy, and extensive data analysis. The reader is referred to Johnson and others (2012) and Jackson and 


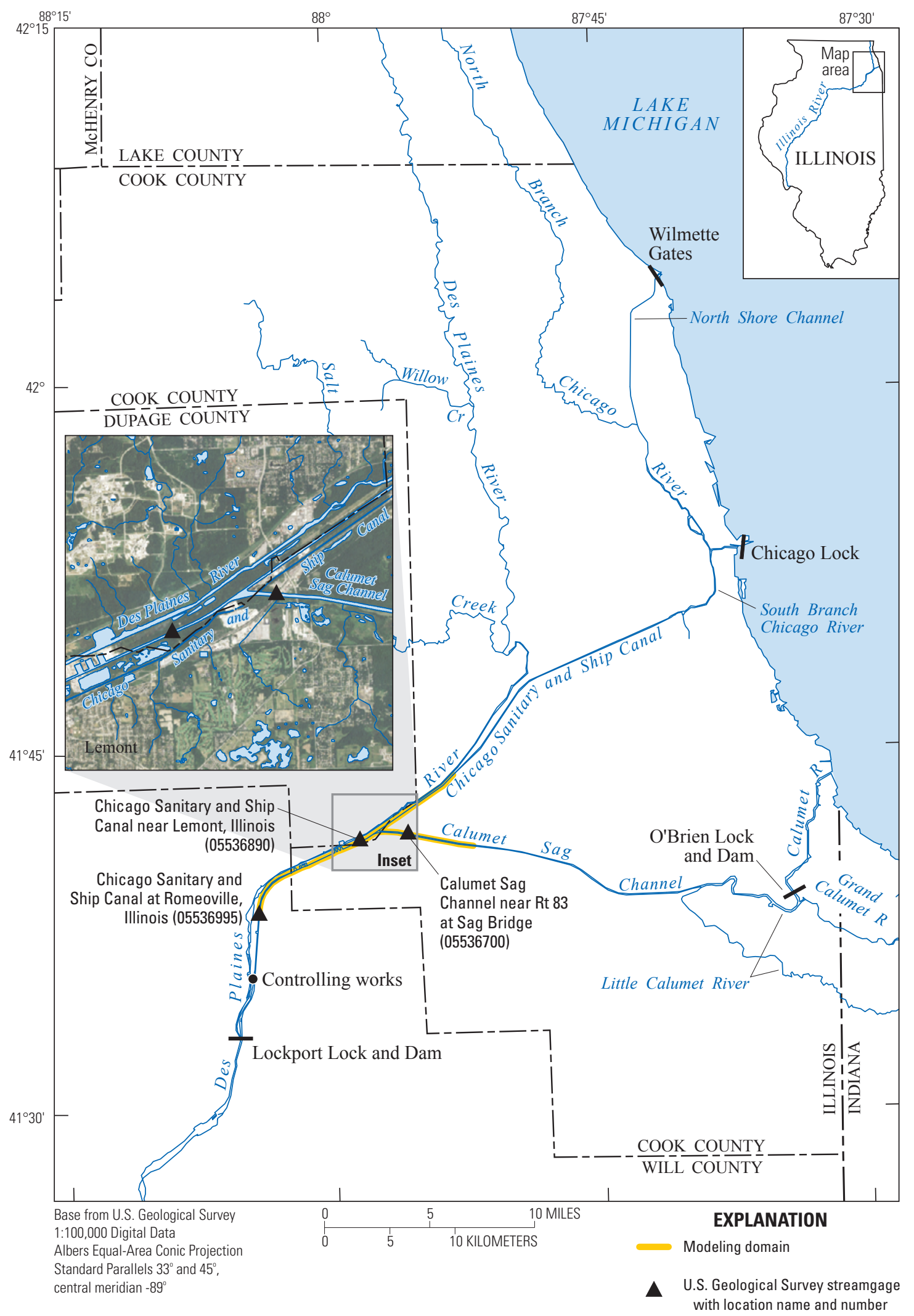

Figure 1. Map of the Chicago Area Waterway System (CAWS) showing the Chicago Sanitary and Ship Canal (CSSC), Calumet Sag Channel, North Branch Chicago River, Little Calumet River, Grand Calumet River, and the other waterways in and near Chicago, Illinois. Locations of USGS streamgages and the extent of the model domain also are shown for reference. 
others (2012) for detailed reviews of the streamgaging practices at this site and the unique hydraulics of this system. This report describes the investigation of the potential for hysteresis in index-velocity ratings for two types of acoustic velocity meters installed at the USGS streamgage on the CSSC near Lemont, Ill. (05536890).

The intense scrutiny of the Lake Michigan diversion accounting requires a high degree of accuracy and reliability in the USGS discharge measurements and the methods to compute continuous discharge in the CSSC. The current primary gage on the CSSC near Lemont, Ill., is an acoustic velocity meter (AVM) (fig. 2). This time-of-travel meter measures a bank-to-bank average velocity (index velocity) at specific elevations above the bed in the measurement reach, which is related to a mean cross-sectional velocity (discharge divided by the rated area) by an index-velocity rating. Redundancy is provided by a horizontal acoustic Doppler current profiler (H-ADCP), also called an acoustic Doppler velocity meter (ADVM), which serves as the backup gage at this site. The $\mathrm{H}-\mathrm{ADCP}$ measures velocity in a series of "cells" at a specified distance in front of the right bank-mounted unit (fig. 2). Technical limitations prevent the unit from measuring near either bank (the unmeasured near-bank distance is a function of the unit configuration as well as channel geometry and water depth). Currently, the H-ADCP data are used only to estimate discharge during periods of missing record from the primary gage. The AVM and H-ADCP were compared in detail by Jackson and others (2012), who concluded that the H-ADCP was capable of replacing the AVM as the primary gage. In addition, Jackson and others (2012) reviewed and analyzed the complex hydraulics present in the system and the challenges this system presents to those applying standard continuous streamgaging techniques at this site.

Of particular interest in the present analysis is the location of the streamgage relative to the confluence of the CSSC and the Calumet Sag Channel (Cal-Sag) and the possibility that the proximity of this gage to the confluence might result in hysteresis in the index-velocity rating curve due to variations in flow distribution downstream of this confluence during high-flow events. With regard to rating curves in open-channel hydraulics, hysteresis can be defined as the formation of looped rating curves during unsteady flows. Specifically, the rating curves for the rising and falling limbs of a flood wave are not coincident, resulting in a loop-shaped rating curve for the entire event. Hysteresis in index-velocity ratings has been documented at tidally affected sites (for example, Ruhl and Simpson, 2005) due to the large changes in flow distribution in the measurement section over the course of the tidal cycle. Changes in flow distribution in the section can result in two separate index velocities for the same discharge (or same mean cross-sectional velocity), leading to hysteresis. Although hysteresis in index-velocity ratings at nontidal sites is theoretically possible, documentation of this phenomenon is scarce. In contrast, hysteresis in stage-discharge ratings is well documented for backwater-affected channels and those with highly unsteady flow conditions. Fread (1975) explained that hysteresis in a stage-discharge rating curve is the manifestation of the fact that the discharge at a given section under unsteady flow conditions is the function not only of stage but also of the energy slope. Mander (1978) further explained that when a wave associated with a high-flow event passes through a given cross section, the effect of the wave front when upstream of the cross section is to increase the approach velocity at the cross section. As the flood peak passes downstream of the cross section, the rear of the wave enhances the backwater effect at the cross section and hence reduces the velocity at the cross section. The consequence of the floodpeak passage through the section is such that for the same stage, the discharge is higher during the rising stage than the falling stage. Consequently, one can obtain multiple values of the discharge for the same stage, depending on whether the stage measurement was made on the rising limb or the falling limb of the passing flood wave. To combat the problem of hysteresis in stage-discharge ratings, engineers and researchers have employed the index-velocity technique for measuring the discharge at a given section.

The objective of this report is to determine what conditions are required in the CSSC near Lemont, Ill., to generate hysteresis in the index-velocity ratings for the AVM and H-ADCP sampling configurations. Furthermore, this report examines whether those conditions are present at the site on the basis of observed data and simulations from conceptual and three-dimensional models.

\section{Theoretical Analysis}

A theoretical analysis of the conditions under which hysteresis is present in the index-velocity rating curve for the Chicago Sanitary and Ship Canal near Lemont, Ill., allows the flexibility to test flow distributions that might not otherwise be present in field data or hydrodynamic models driven by observed boundary conditions. The following conceptual model tests more than 38,000 simulated flow events to determine the potential for hysteresis in the derived index-velocity rating.

\section{Conceptual Model Overview}

In order to determine the conditions required to produce hysteresis in the index-velocity ratings for the CSSC near Lemont, Ill., a conceptual model was developed. The model utilizes observed high-flow event data (stage and discharge) and the beta distribution to prescribe transverse velocity distributions (Seo and Baek, 2004) in order to investigate the sensitivity of the H-ADCP and AVM index velocity to flow distribution in the section (fig. 3). The observed hydrograph is divided into the rising limb and falling limbs (fig. 4A), and stage $(G)$ is converted to area $(A)$ by using the stage-area rating for this gage $\left(A\left(f t^{2}\right)=139.83 G(f t)+670.39\right.$; Jackson and others, 2012) (figs. $4 B$ and $C$ ). Mean velocity for the section 

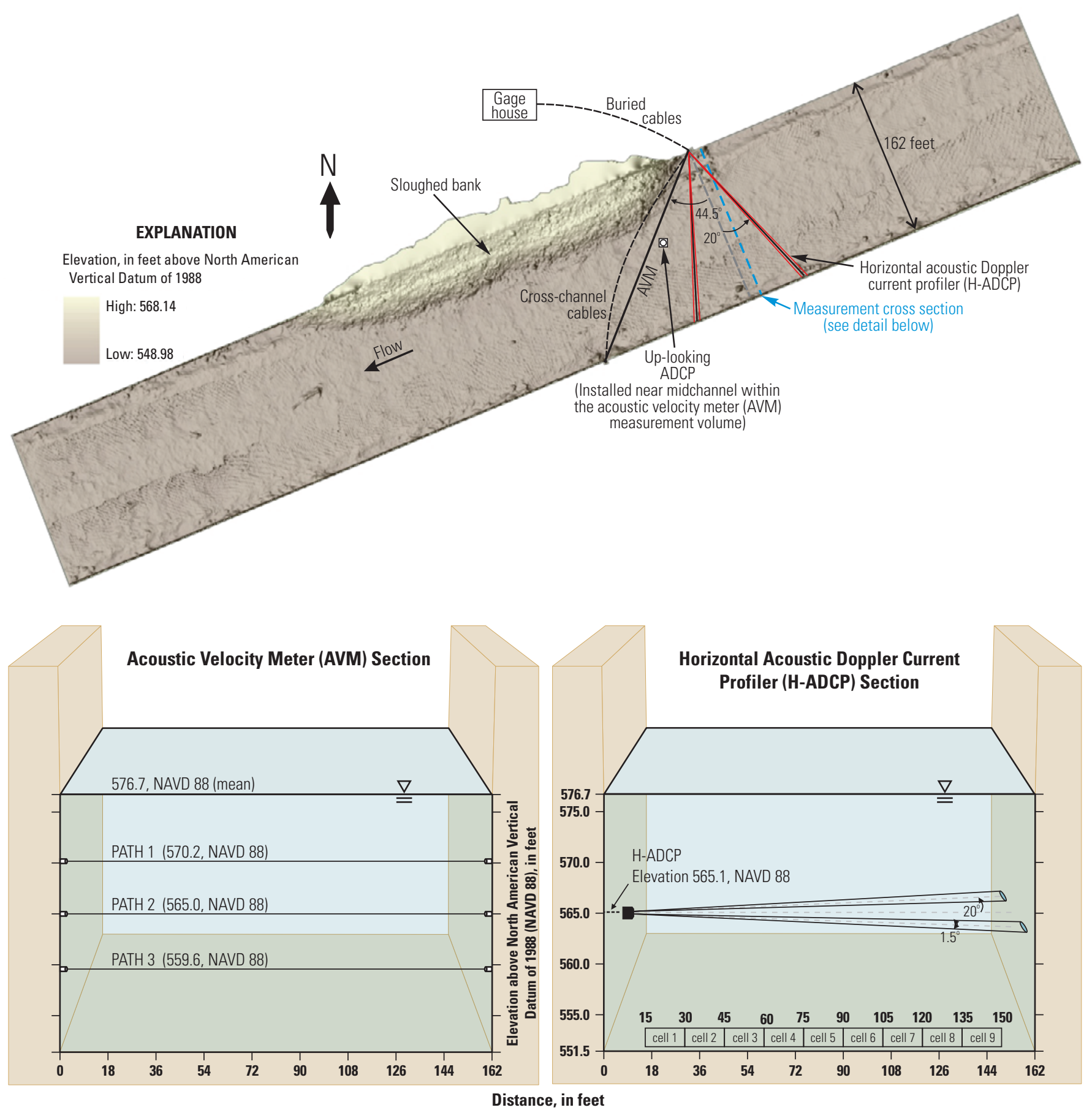

Channel cross section and bathymetry simplified for schematic

Figure 2. Schematic showing the instrument configurations and the channel bathymetry at the U.S. Geological Survey streamgage on the Chicago Sanitary and Ship Canal near Lemont, Illinois (05536890). The upper figure is in plan view. 
$\left(V_{\text {mean }}\right)$ is then computed by dividing the discharge $(Q)$ by the rated area $(A)$ and then plotted as the ordinate for the indexvelocity rating. The mean velocity is then used in conjunction with the coefficients of the beta density function $(\alpha, \beta$, and $\Delta)$ to define the transverse velocity profile in the section (see section "Synthetic Transverse Velocity Profiles"). The coefficients of the beta density function are allowed to vary over the hydrograph, resulting in a variable shape of transverse velocity profile (fig. $4 H$ ). The index velocity $\left(V_{\text {indx }}\right)$ is then computed by sampling the transverse velocity profile at each time step in the same configuration as the H-ADCP and AVM and plotted as the abscissa for the index-velocity rating. This workflow allows one to take observed data (stage and discharge), synthetically distribute the flow across the section, resample the flow using field-instrument configurations, and generate an index-velocity rating for each simulation. Replicating this process for a large range of flow distributions (the example in figure 4 is only one of 38,400 simulations run) allows one to test the conditions required to generate hysteresis in the indexvelocity rating in the CSSC near Lemont, Ill. The conceptual model was built and run in Matlab ${ }^{\circledR}$.

\section{Details of the Conceptual Model}

This section presents the details of the conceptual model diagramed in figure 3 . Each step within the flowchart in figure 3 is discussed in detail, and key terms and methods are defined. In addition, the methods used to generate the large number of scenarios are presented.

\section{Pseudo-Synthetic Hydrograph}

The hydrograph and stage data used in the conceptual model are based on observed data from the CSSC near Lemont during a large $\left(13,200-\mathrm{ft}^{3} / \mathrm{s}\right.$ peak flow) event in November 2010 (fig. 4A). For comparison, table 1 lists the annual mean and peak flows for the CSSC near Lemont, Ill. (05536890), for 2006 to 2012. Ten-minute observations of stage and discharge during the November 2010 event were smoothed by using a 110 -minute moving average to remove noise and temporal variations due to lockages and other disturbances in the system (see Jackson and others, 2012). The derivative of the discharge $(d Q / d t)$ is used to define the rising limb $(d Q / d t>0)$ and falling limb $(d Q / d t<0)$ of the hydrograph (fig. $4 A)$.

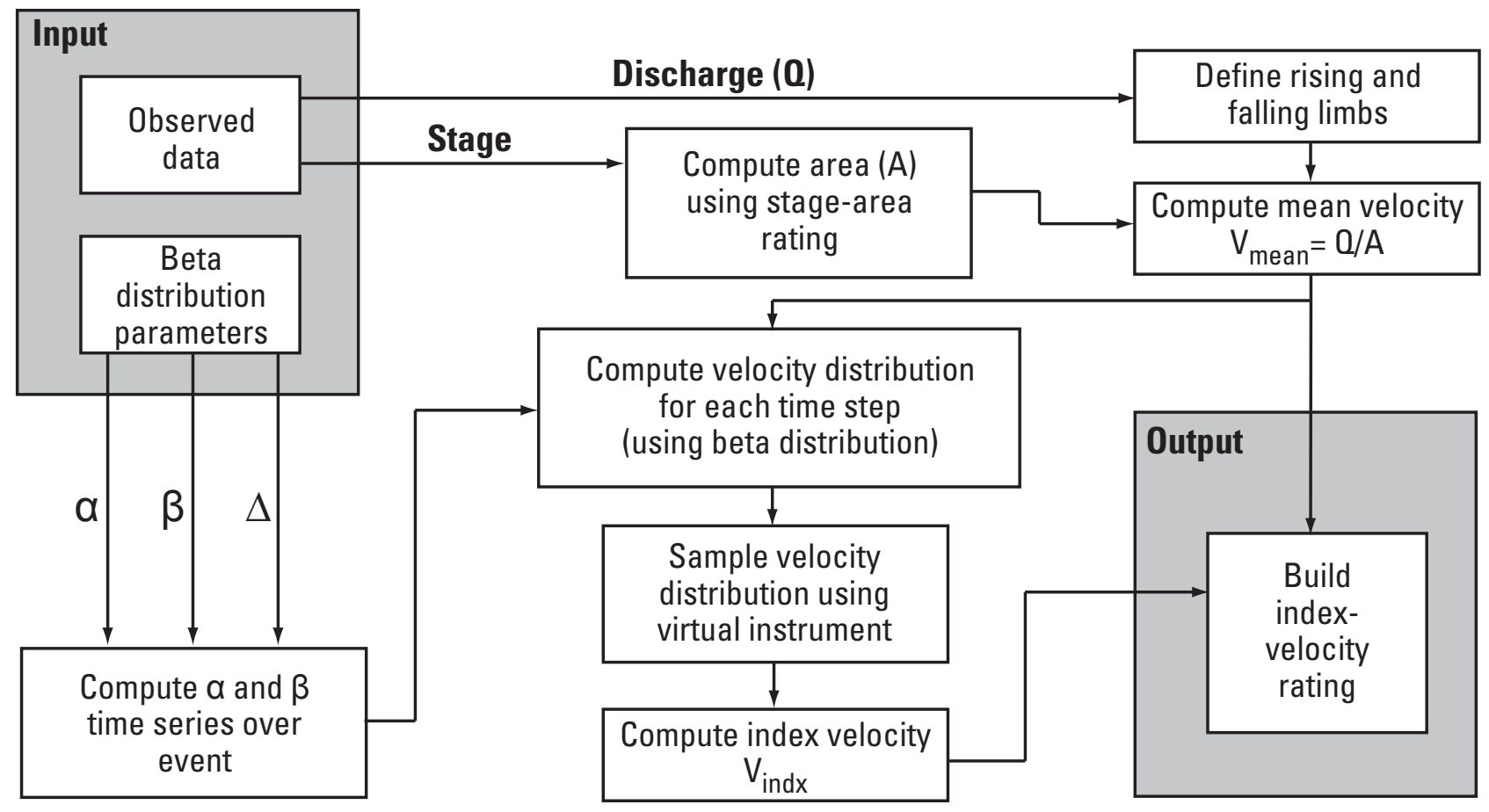

Figure 3. Workflow schematic for the conceptual model. 

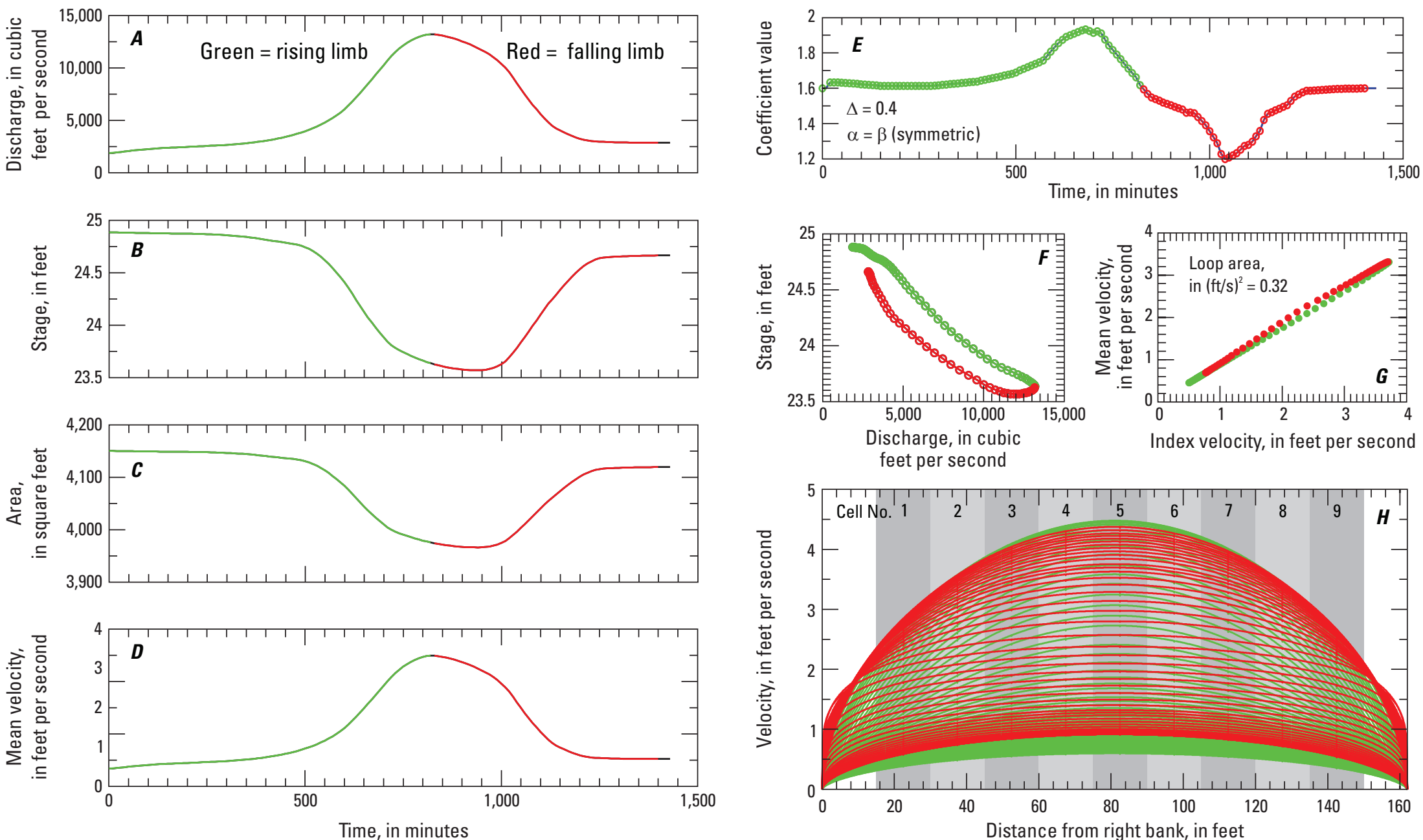

Figure 4. Compilation plot for a single simulation using a symmetric flow distribution and the sampling configuration for the horizontal acoustic Doppler current profiler. Plots on the left: $A$, the observed hydrograph; $B$, the observed stage; $C$, the computed cross-sectional area; and $D$, the computed mean velocity. Plots on the right: $E$, the time series of beta distribution coefficients; $F$, the stage-discharge loop; $G$, the index-velocity rating; and $H$, the temporal evolution of the transverse velocity profile over the event as defined by the beta distribution. 
Table 1. Annual mean and peak discharge measured at USGS streamgage on the Chicago Sanitary and Ship Canal near Lemont, Illinois (05536890), water years 2006 to 2012.

[ $\mathrm{ft}^{3} / \mathrm{s}$, cubic feet per second]

\begin{tabular}{cccl}
\hline $\begin{array}{c}\text { Water } \\
\text { year }\end{array}$ & $\begin{array}{c}\text { Mean discharge } \\
\left(\mathbf{f t}^{3} / \mathbf{s}\right)\end{array}$ & $\begin{array}{c}\text { Peak discharge } \\
\left(\mathbf{f t}^{3} \mathbf{s} \mathbf{s}\right)\end{array}$ & \multicolumn{1}{c}{ Date of peak } \\
\hline 2006 & 2,615 & 14,632 & September 13, 2006 \\
2007 & 3,167 & 16,572 & August 23, 2007 \\
2008 & 3,096 & 20,053 & September 14, 2008 \\
2009 & 3,267 & 18,649 & December 27, 2008 \\
2010 & 2,967 & 18,984 & July 24, 2010 \\
2011 & 2,838 & 16,862 & July 23, 2011 \\
2012 & 2,181 & 13,366 & August 27, 2012 \\
\hline
\end{tabular}

\section{Synthetic Transverse Velocity Profiles}

The transverse velocity distribution across the measurement section is defined by using the beta distribution (Seo and Baek, 2004). The dimensionless transverse velocity distribution is defined by the beta density function

$$
\frac{u}{V_{\text {mean }}}=\frac{\Gamma(\alpha+\beta)}{\Gamma(\alpha) \Gamma(\beta)}\left(y^{\prime}\right)^{\alpha-1}\left(1-y^{\prime}\right)^{\beta-1}, 0<y^{\prime}<1
$$

where $\quad u \quad$ is the depth-averaged velocity;

$y^{\prime} \quad$ is the normalized transverse coordinate defined as $y^{\prime}=y / W$, where $y$ is the transverse coordinate and $W$ is the channel width; and

$\alpha \quad$ is a positive coefficient of the beta density function; and

$\beta \quad$ is a positive coefficient of the beta density function; and

$V_{\text {mean }} \quad$ is the mean velocity for the cross section; and

$\Gamma \quad$ is the gamma function defined as

$$
\begin{aligned}
& \Gamma(\alpha)=\int_{0}^{\infty} x^{\alpha-1} e^{-x} d x, \quad \alpha>0 \\
& \Gamma(\beta)=\int_{0}^{\infty} x^{\beta-1} e^{-x} d x, \quad \beta>0
\end{aligned}
$$

The beta distribution has been found to be capable of representing the complete spectrum of properties of the transverse velocity distribution for natural streams (Seo and Baek, 2004). Although the CSSC is not a natural stream, the beta distribution is capable of replicating the transverse velocity distribution in the CSSC near Lemont (Jackson and others, 2012). The coefficients $\alpha$ and $\beta$ in equation 1 can be varied over a large range of values to generate largely varying profiles. If $\alpha$ and $\beta$ are equal, the velocity distribution is symmetric about the channel centerline. Larger values of $\alpha$ and $\beta$ generate a peaked profile with more flow in the center of the channel, whereas low values of $\alpha$ and $\beta$ generate a more flat or uniform profile. If $\alpha$ and $\beta$ are not equal, the flow is skewed to the left bank for $\alpha>\beta$ and skewed to the right bank for $\beta>\alpha$. In this case, the banks are defined looking downstream with $y^{\prime}=0$ on the right bank and $y^{\prime}=W$ on the left bank.

The beta distribution was utilized by specifying $V_{\text {mean }}$ (fig. $4 D$ ) and time series for $\alpha$ and $\beta$ over the rising and falling limbs of the hydrograph (fig. $4 E$ ) to generate a velocity profile at each time step (fig. 4H). Change in the coefficients $\alpha$ and $\beta$ was driven by a normalized value of $d Q / d t$ multiplied by $\Delta$, a dimensionless parameter representing the total change in the values of the coefficients $\alpha$ and $\beta$ over each limb. Physically, $\Delta$ can be thought of as a measure of the total prescribed change in the shape of transverse velocity profile over the high-flow event and is set by the user. Larger values of $\Delta$ will result in greater variation in the shape of the velocity profile over an event. Using the rate of change of $Q$ to drive the change in $\alpha$ and $\beta$ links the shape of the transverse profiles to the acceleration and deceleration of the flow. With this approach, the profiles become more peaked on the rising limb of the hydrograph (that is, $\alpha$ and $\beta$ increase) and more flat on the falling limb of the hydrograph (lower $\alpha$ and $\beta$ ) (fig. 4H). This scenario allows the greatest variance in the flow profile between the rising and falling limbs of the hydrograph, thus producing the greatest likelihood of generating hysteresis. This synthetic variability in the flow distribution over an event will be compared with observed distributions later in this report.

\section{Index-Velocity Rating Development}

Every simulation run by using the conceptual model resulted in a set of transverse velocity profiles that vary over the event hydrograph. In order to build an index-velocity rating from these data, one needs to compute the associated $V_{\text {indx }}$ for every value of $V_{\text {mean }}$. Index velocities were computed for each time step by sampling each transverse velocity profile, using the field configuration for the AVM (single, fullwidth cell) and H-ADCP (nine 15-ft cells with unmeasured areas near both banks; see figs. 2 and $4 H$ ). In addition, several other configurations were tested including a single 15 -ft cell in the center of the channel and five cells centered between the channel centerline and $15 \mathrm{ft}$ from the right bank (measuring only the right half of the flow) to test the sensitivity of these other configurations to the variable flow distributions. The index velocity, $V_{i n d x}$, was then computed for each configuration, at each time step, as the average of the mean cell velocities (that is, for the H-ADCP, $V_{\text {ind }}$ is the average of the mean velocities from each of the nine sampling cells). Therefore, for each simulation, $V_{\text {mean }}$ was plotted against $V_{\text {indx }}$ and points were color coded by the rising limb (green) or falling limb (red) of the hydrograph to determine whether hysteresis was present (fig. $4 G$ ). For every case in which a loop was generated, the area of the loop, computed as the total area between the two limbs, was computed as a measure of the magnitude of the hysteresis (a large loop area indicates substantial hysteresis). 


\section{Simulations Summary}

In order to test a large range of possible flow distributions that could potentially lead to hysteresis, a large number of simulations were run for each instrument configuration. The initial beta distribution coefficients were varied from 1 to 5 at increments of 0.1 , leading to 1,600 combinations of $\alpha$ and $\beta$. In addition, six different values of $\Delta$ were tested ( 0.0 to 0.5 at increments of 0.1 ) to examine the sensitivity of hysteresis to the total change in the coefficient value over the hydrograph. Therefore, 9,600 simulations were computed for each of the four instrument configurations (38,400 simulations total), with each simulation having an associated index-velocity rating curve and loop area. Figure 5 presents examples of index-velocity rating curves for six different simulations (all $\mathrm{H}-\mathrm{ADCP}$ configuration) covering a large range of hysteresis magnitude (loop area). All computations were completed with the same observed hydrograph (fig. $4 A$ ) and stage record (fig. $4 B$ ).

\section{Hysteresis Analysis}

The results of the conceptual model are discussed in this section and analyzed to understand the conditions required for hysteresis in the index-velocity rating in the Chicago Sanitary and Ship Canal near Lemont, Ill. In addition to the field configurations of the AVM and H-ADCP, several other common index-velocity sampling configurations are analyzed to determine their potential for hysteresis.

\section{Effect of Flow Distribution and Sampling Configuration}

Based on results of the conceptual model, hysteresis is most prominent in index-velocity ratings developed by using the H-ADCP sampling configuration for conditions in which the transverse flow profile is highly skewed to either bank and changes shape significantly between the rising and falling limbs of the hydrograph (fig. 6). With the exception of the $\Delta=0$ case, all simulations showed substantial hysteresis for flow profiles with extreme skewness to either bank. Hysteresis arises in this situation because of a combination of unmeasured areas near both banks and the magnitude and overall change in the flow profile within the unmeasured areas near the banks. Although subtle, the hysteresis is slightly larger for a flow skewed to the right bank relative to a flow skewed to the left bank. This is likely caused by the larger unmeasured zone near the right bank ( $15 \mathrm{ft}$ ) compared to the smaller unmeasured zone near the left bank (12 ft).

For the $\Delta=0$ case (no change in the shape of the profile over the hydrograph, only changes in magnitude), no hysteresis was observed for any of the 1,600 cases simulated. In general, as $\Delta$ increases, there is greater overall change in the shape of the profile over the hydrograph, and hysteresis becomes more prominent (fig. 6). However, for the H-ADCP sampling configuration, hysteresis can be minimal even for large $\Delta$ if the flow is symmetric. In the case of a symmetric flow, hysteresis is greater for a flat flow profile than for a peaked flow profile. This condition likely arises because the peaked profile results in less overall flow in the unmeasured zones near the edges.

When the entire cross section is measured and there are no unmeasured zones near the banks, as in the case of the AVM configuration, no hysteresis is observed in the conceptual model for any of the 9,600 cases simulated (fig. 7). Therefore, hysteresis is not caused solely by change in the profile over the hydrograph but rather by such changes that occur in unmeasured zones within the cross section and their overall influence on the computed index velocity. This result implies that instruments that measure the full width of a cross section with no unmeasured zones (such as the AVM) are not affected by hysteresis induced by variability in the transverse velocity profile. The AVM sampling configuration was modeled in this case as a single cell spanning the full width of the channel. Because the beta distribution represents the depth-averaged flow distribution, these results should hold for all three paths of the AVM, as well as for the index velocity built from their composite (see Jackson and others, 2012).

The large dependency of hysteresis on the sampling configuration of the instrument used to measure the index velocity suggests that other potential sampling configurations for the CSSC near Lemont should be tested to determine their potential for hysteresis. As mentioned previously, the current (2013) configuration of the H-ADCP measures an index velocity by averaging nine 15 -ft sampling cells evenly spaced across the channel with unmeasured zones near both banks (see fig. 2). Two additional sampling configurations were chosen on the basis of potential use of such a configuration at the site. The first alternative sampling configuration tested was a single, 15 -ft sampling cell along the channel centerline. Such a configuration might be used with both side-looking instruments as well as bottom-mounted up-looking ADCPs. The second alternative sampling configuration tested was a configuration with five evenly distributed sampling cells centered between the center of the channel and $15 \mathrm{ft}$ from the right bank. This configuration approximates a common field situation when using instruments that do not have the capability to profile across the entire cross section. Neither of these two configurations have been field tested at this site. The remainder of this section presents the findings for these alternative configurations.

Hysteresis was pronounced in the case of a single sampling cell in the center of the channel for a large range of flow distribution scenarios (fig. 8). This configuration was found to be the most susceptible to hysteresis of the configurations tested. Total loop areas, representing the strength of the hysteresis, were found to be nearly twice that of the $\mathrm{H}-\mathrm{ADCP}$ configuration case. Like the other configurations tested, the case of $\Delta=0$ resulted in no hysteresis. However, as $\Delta$ increased, hysteresis increased, with the greatest loop areas observed for flat, skewed profiles. The least hysteresis was observed for highly peaked, symmetric flow. This is likely because, for such a flow distribution, the center sampling cell 

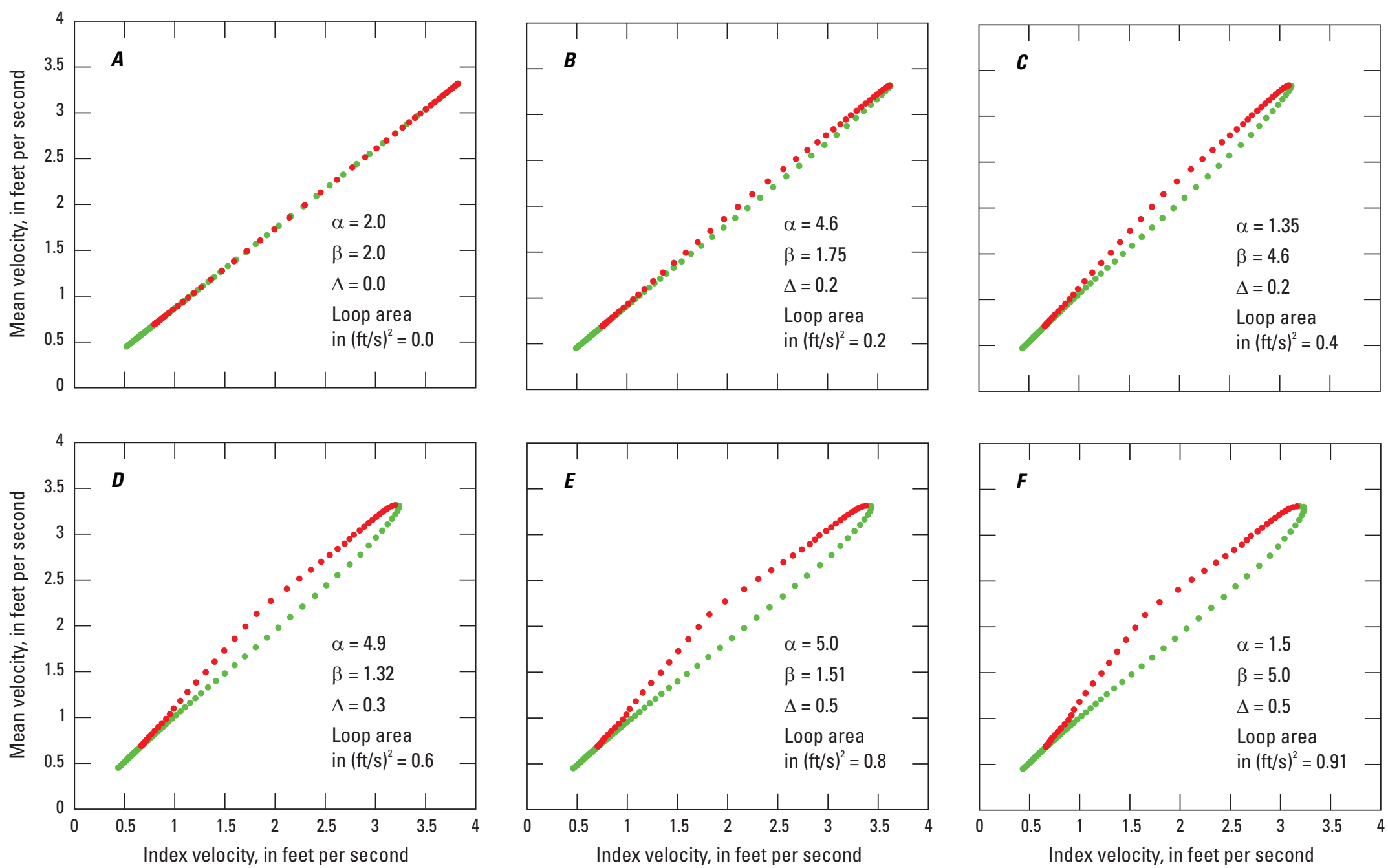

Figure 5. Index-velocity rating curves for six simulations using the H-ADCP configuration and beta density function coefficients as shown in each figure. Green points denote the rising limb of the hydrograph, and red points denote the falling limb. The loop area, a measure of the strength of the hysteresis, is displayed in each figure for reference. 

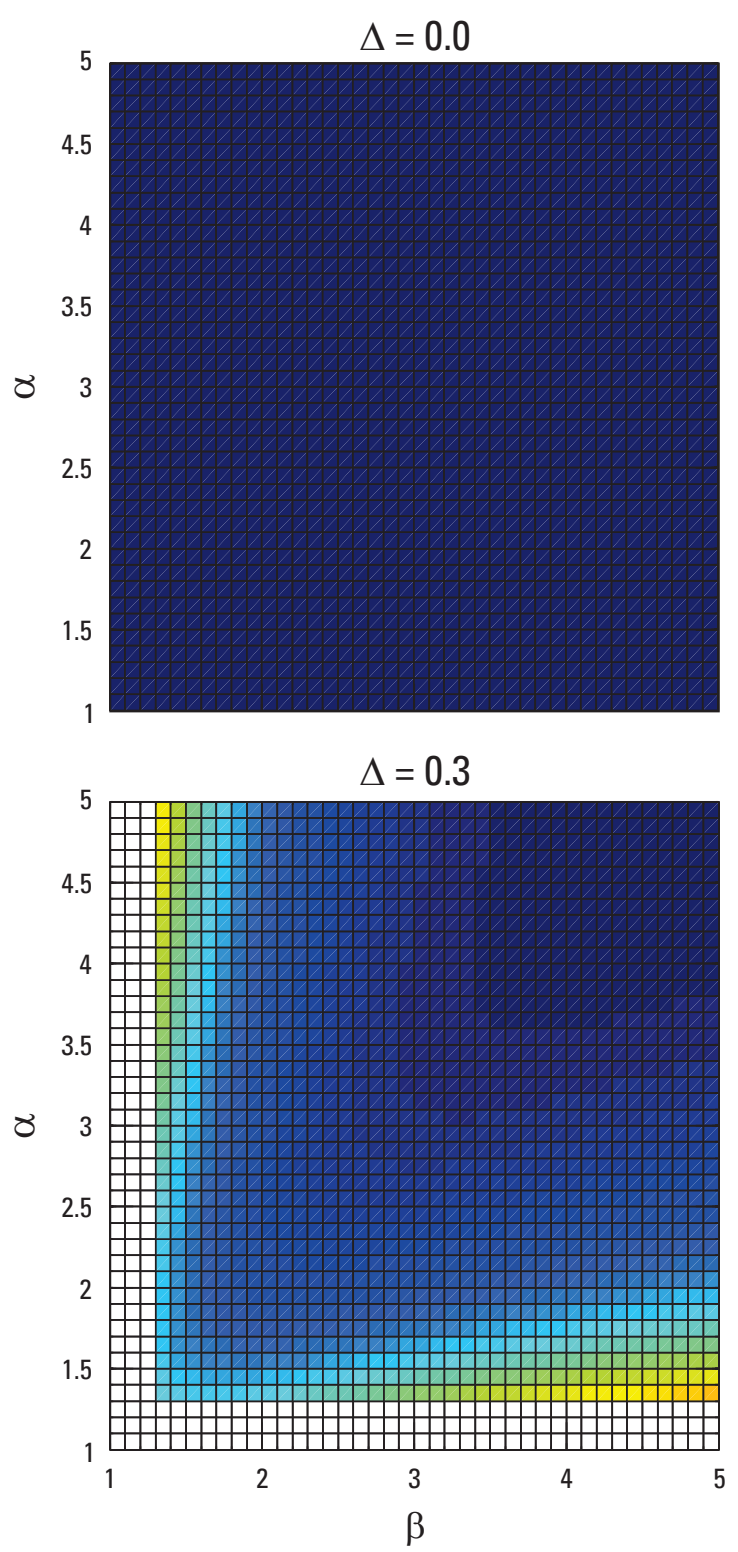

$\Delta=0.1$

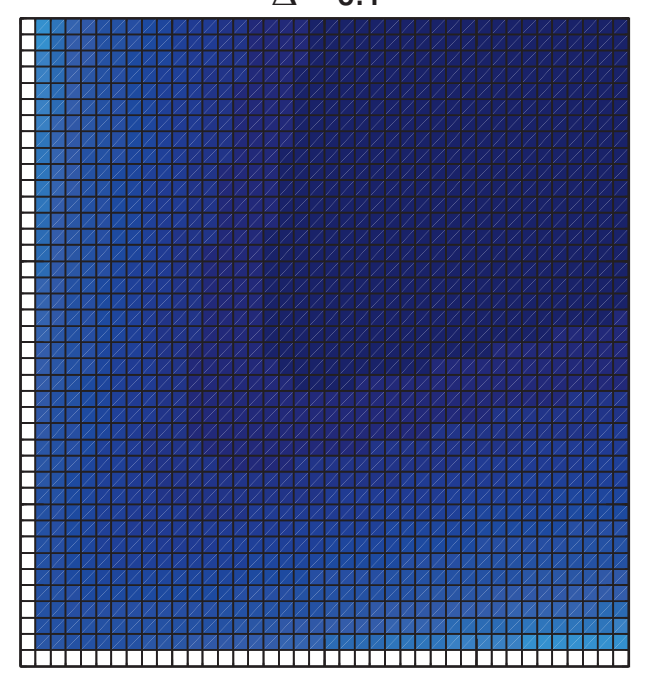

$\Delta=0.4$

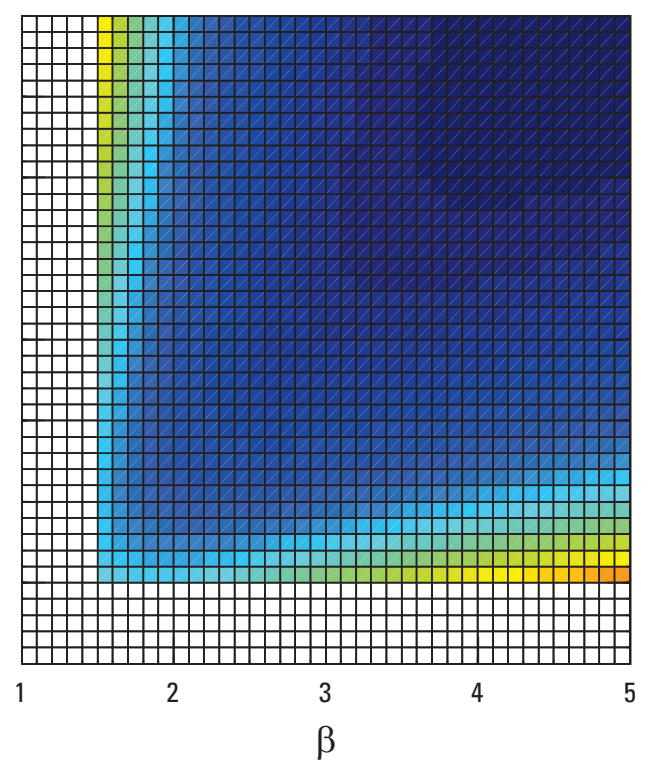

$\Delta=0.2$

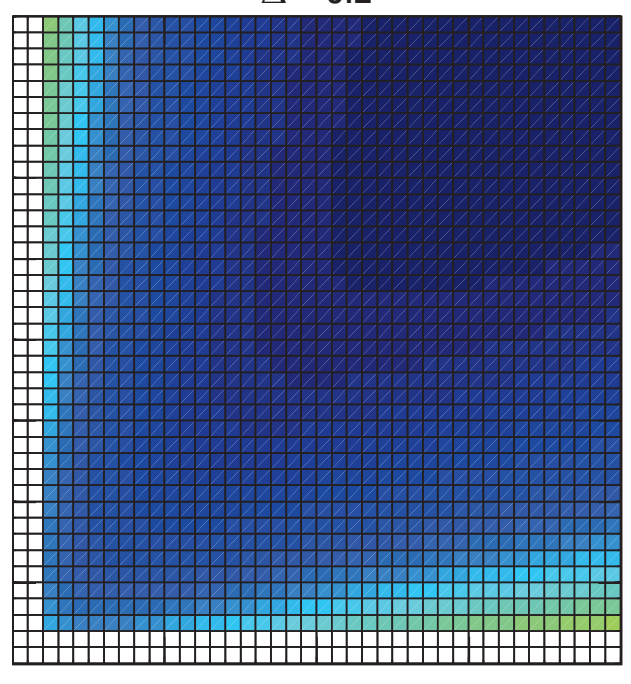

$\Delta=0.5$

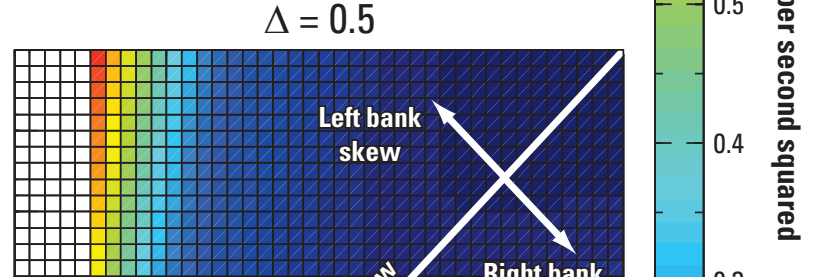

Right bank $\quad-0.3$

skew

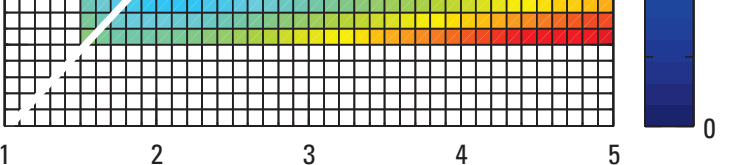

$\beta$

Figure 6. Six-panel plot showing the sensitivity of the horizontal acoustic Doppler current profiler (H-ADCP) sampling configuration to various distributions of the transverse velocity profile over a typical high-flow event. The flow profile is defined by the beta density function using coefficients $\alpha$ and $\beta, \Delta$ specifies the overall change in $\alpha$ and $\beta$ over the event, and hysteresis is quantified by using the loop area. Simulations in which either $\alpha$ and $\beta$ fall below unity are omitted from analysis because inverted profiles are not likely to occur in nature. 

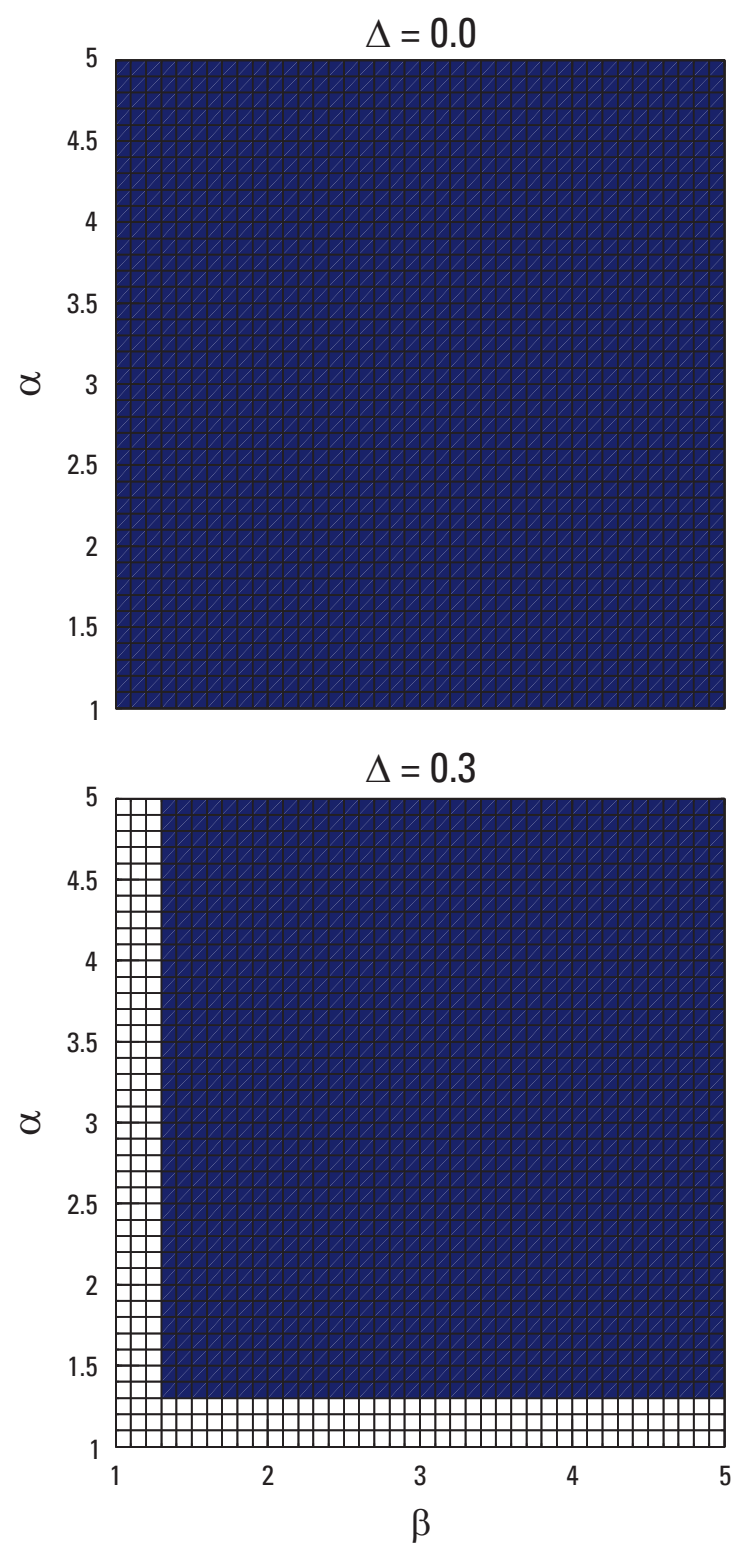

$\Delta=0.1$

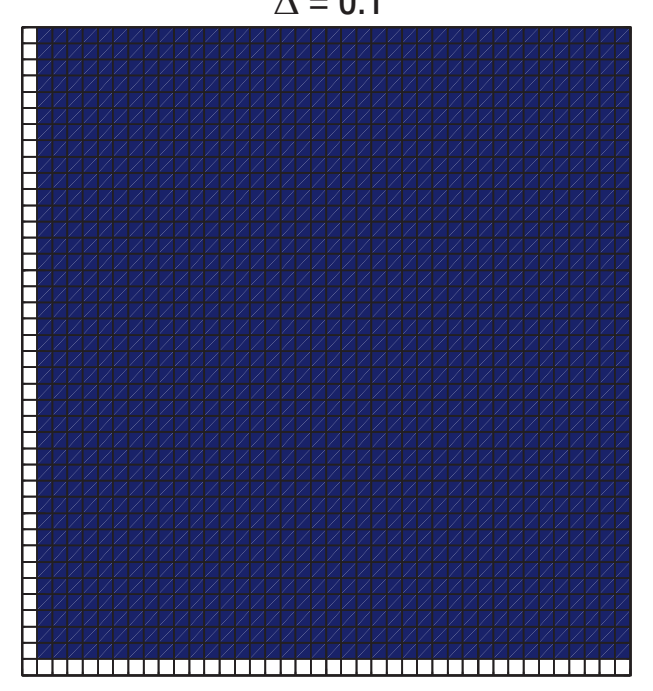

$\Delta=0.4$

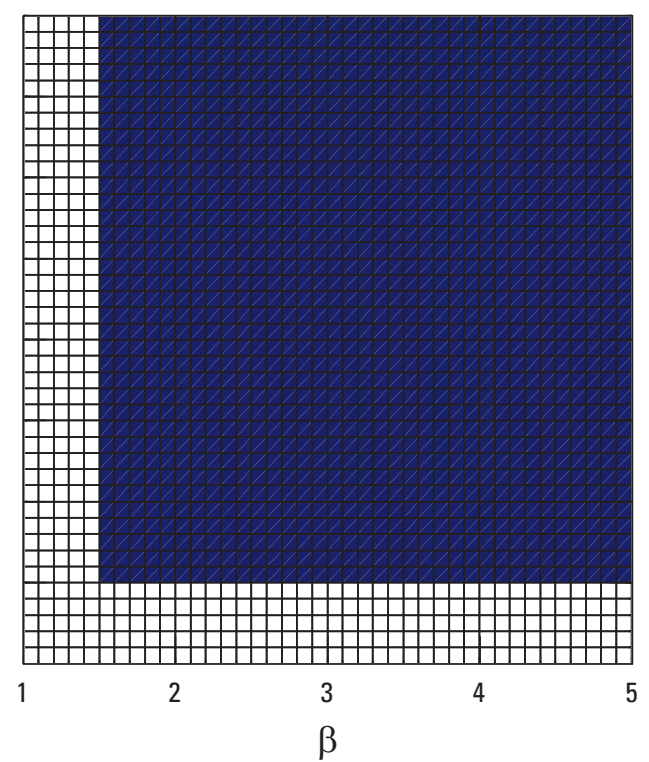

$\Delta=0.2$

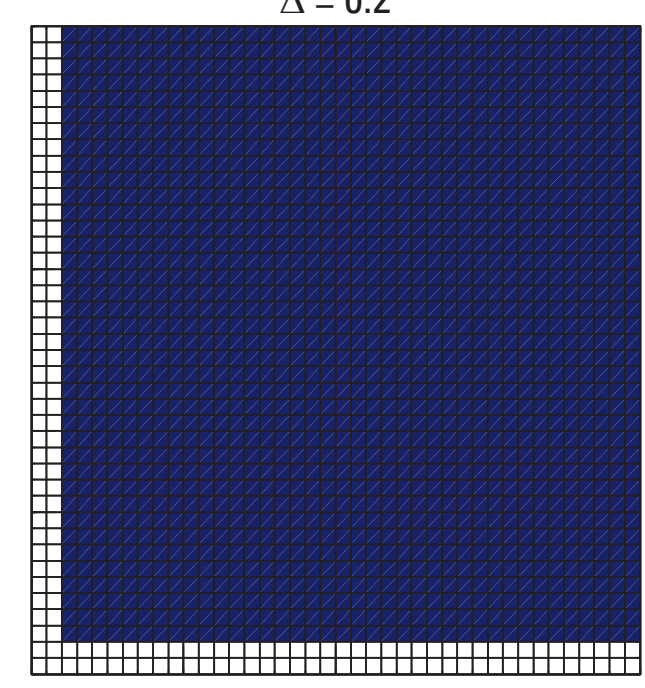

$\Delta=0.5$

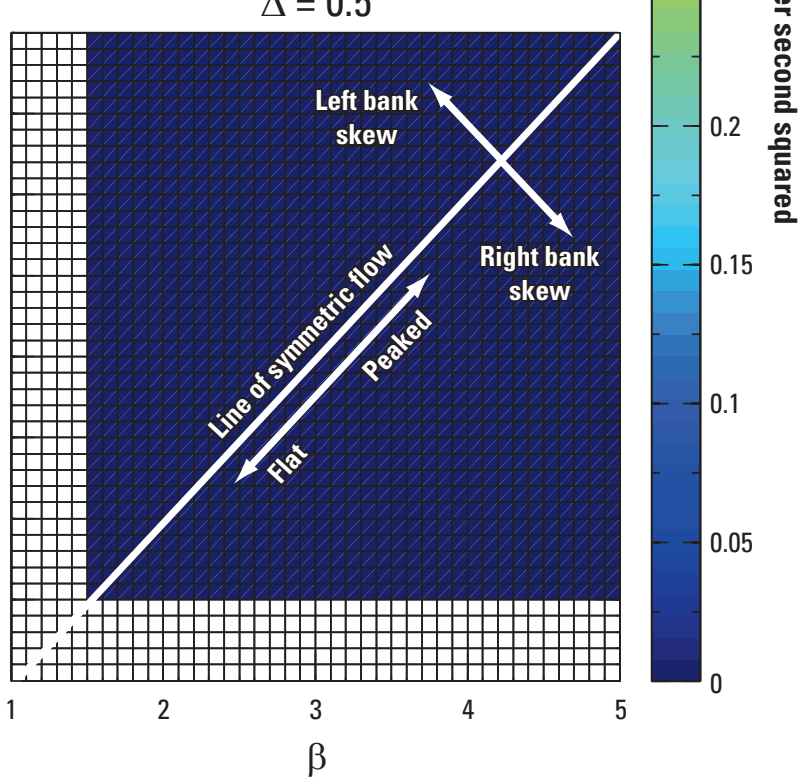

Figure 7. Six-panel plot showing the sensitivity of the acoustic velocity meter (AVM) sampling configuration to various distributions of the transverse velocity profile over a typical high-flow event. The flow profile is defined by the beta density function using coefficients $\alpha$ and $\beta, \Delta$ specifies the overall change in $\alpha$ and $\beta$ over the event, and hysteresis is quantified by using the loop area. Simulations in which either $\alpha$ and $\beta$ fall below unity are omitted from analysis because inverted profiles are not likely to occur in nature. 

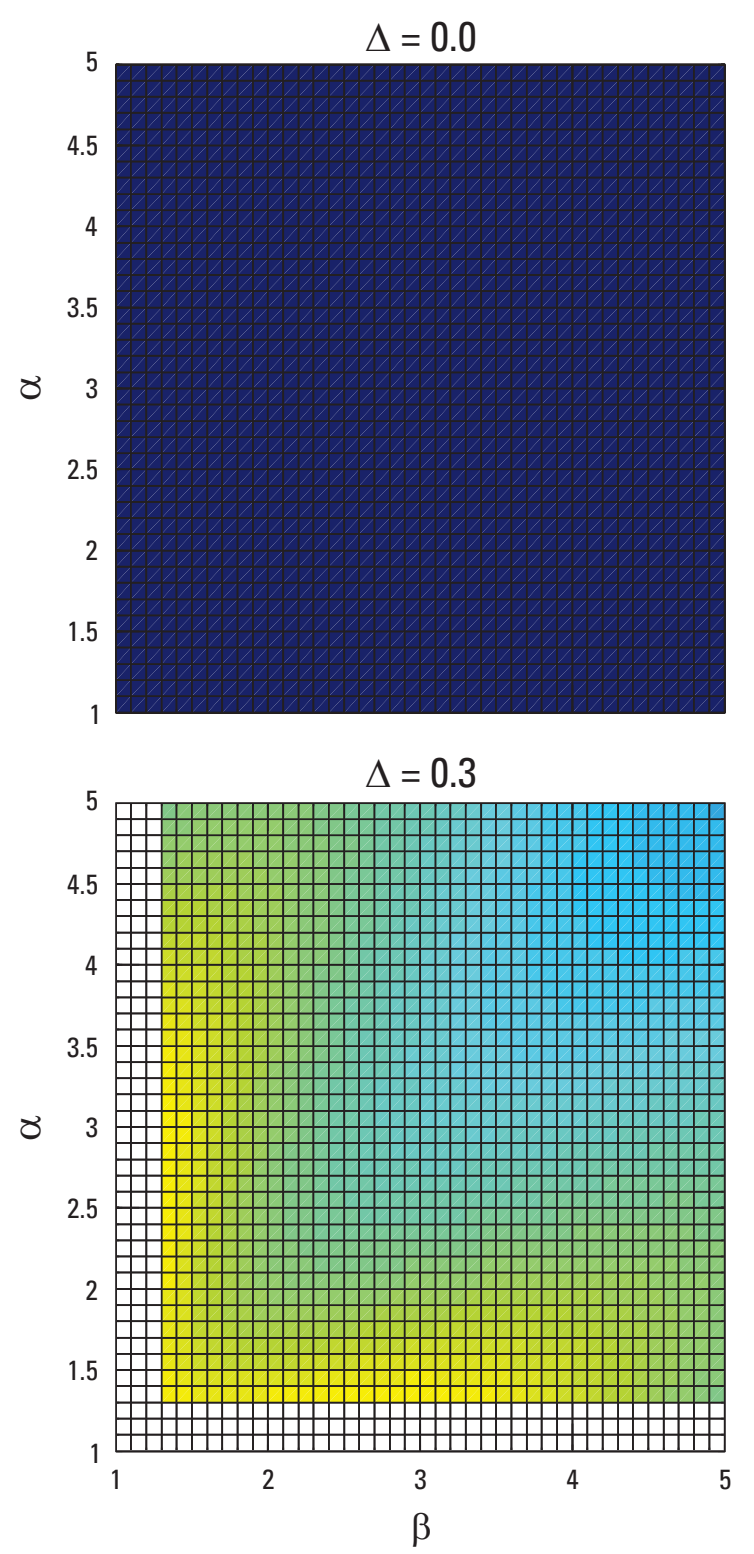

$\Delta=0.1$

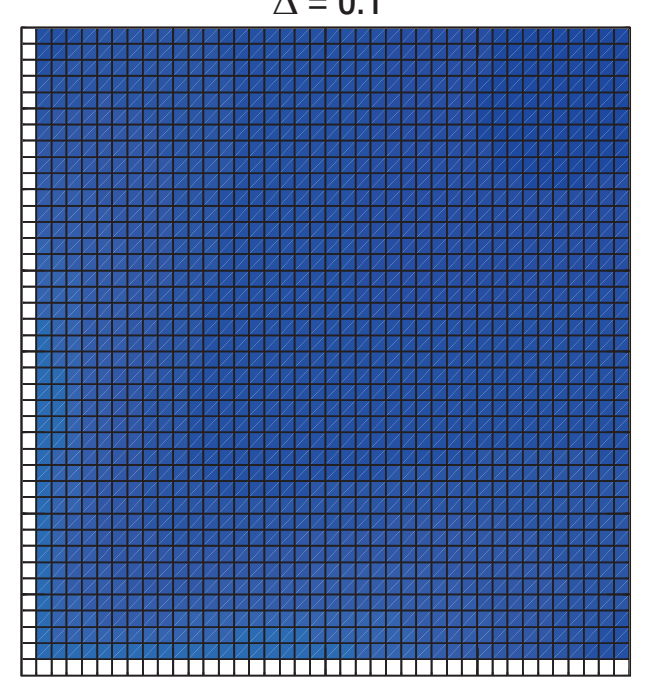

$\Delta=0.4$

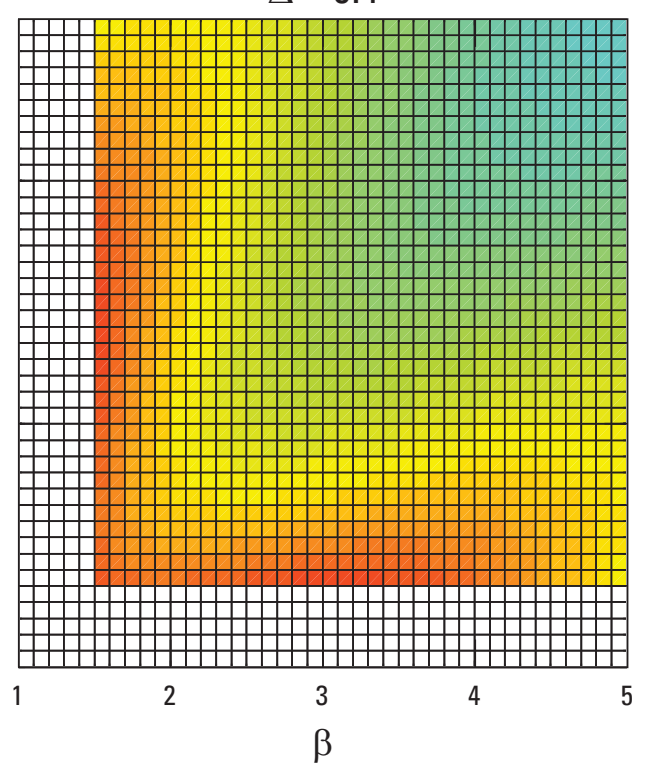

$\Delta=0.2$

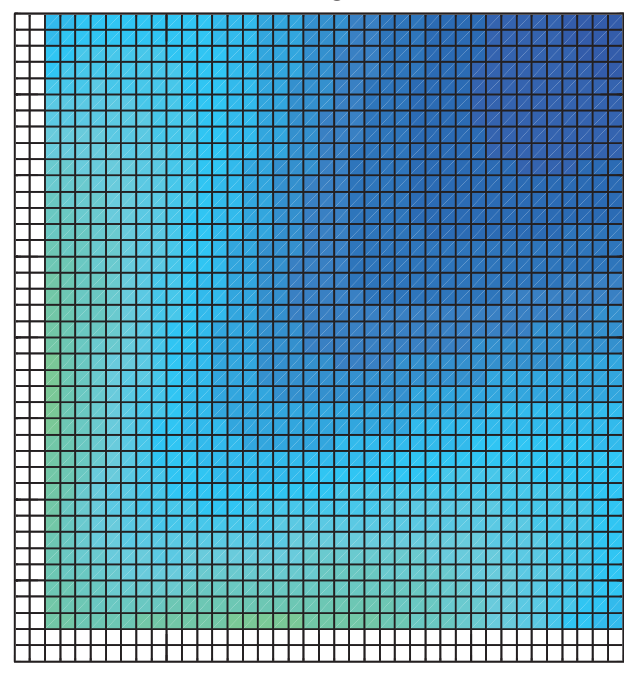

$\Delta=0.5$

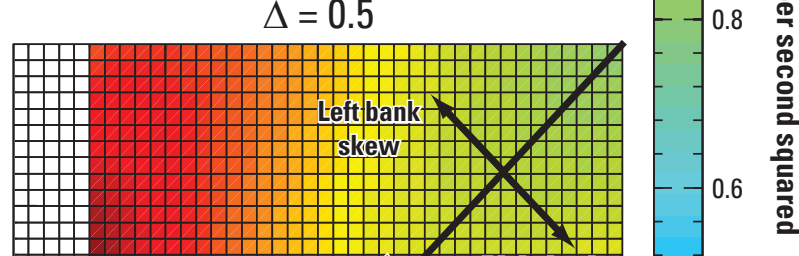

Figure 8. Six-panel plot showing the sensitivity of a single 15-foot, centered-cell sampling configuration to various distributions of the transverse velocity profile over a typical high-flow event. The flow profile is defined by the beta density function using coefficients $\alpha$ and $\beta, \Delta$ specifies the overall change in $\alpha$ and $\beta$ over the event, and hysteresis is quantified by using the loop area. Simulations in which either $\alpha$ and $\beta$ fall below unity are omitted from analysis because inverted profiles are not likely to occur in nature. 
was able to consistently sample the greatest amount of the flow. The widespread existence of hysteresis in this configuration suggests that caution should be used during analysis and rating development for any instrument used in the CSSC near Lemont that is set up in such a configuration. Only a small portion of the cross section is actually measured in this configuration, resulting in substantial hysteresis over a wide range of flow distributions.

Perhaps contrary to intuition, for a sampling configuration in which only flows in the right half of the cross section are being measured (with the exception of the unmeasured zone within $15 \mathrm{ft}$ of the right bank), the greatest hysteresis occurs when the flow is highly skewed to the right bank (fig. 9). In spite of having a large portion of the flow within the sampling volume when the flow is skewed to the right bank, the 15-ft unmeasured area near the right bank leads to significant hysteresis. The loop area for the case of $\alpha=1.5, \beta=5.0, \Delta=0.5$ can be reduced by 84 percent by sampling the full right half of the flow and eliminating the unmeasured zone near the right bank.

It should be noted that whereas loop area may adequately define the strength of hysteresis in a rating curve, the loop area may underestimate the potential uncertainty in the indexvelocity rating due to hysteresis in the case of a large, asymmetric, unmeasured area in the cross section. In this case, a true measure of the effect of hysteresis on index-velocity ratings is the difference between the predicted $V_{\text {mean }}$ for the rising and falling limbs of a hydrograph for the same $V_{i n d x}$. Large differences in $V_{\text {mean }}$ can lead to significant errors in the predicted discharge if the wrong limb of the rating is chosen. Large unmeasured areas in the cross section can create problems by shifting the slope of the rating curve due to a combination of skewed flow distributions and the relative proportion of the flow measured by the index-velocity instrument. For instance, for the configuration in which the right half of the flow is measured (less the $15 \mathrm{ft}$ near the right bank), a flow skewed to the left bank ( $\alpha=5.0, \beta=1.5)$ results in a steep rating curve (fig. 10) because only low velocities are being captured by the instrument. Although the loop area for such a case is only $0.31(\mathrm{ft} / \mathrm{s})^{2}$, the orientation of the loop creates a large difference between the predicted $V_{\text {mean }}$ values for the rising and falling limbs of the rating (fig. 10). When the flow is skewed to the right bank ( $\alpha=1.5, \beta=5.0$ ), the loop is 5 times larger in terms of area, but the slope is less, leading to a smaller difference in the predicted $V_{\text {mean }}$ for the rising and falling limbs of the rating.

\section{Observed Transverse Velocity Distribution and Potential for Hysteresis}

The previous section examined the conditions under which hysteresis is most prominent in the index-velocity rating for the CSSC near Lemont, Ill. Although this exercise provides useful information about the potential for hysteresis at this site, it does not necessarily dictate that hysteresis in the index-velocity rating exists for the range of observed flow conditions. To determine whether the hydraulics in the CSSC near Lemont support conditions for hysteresis, data from the from the H-ADCP can be utilized to examine the temporal variation in the shape of the transverse velocity profile over high-flow events. A total of 102 high-flow events were selected from available data in water years 2010 through 2012. Events were selected to represent a range of flow magnitudes. One-minute velocity observations from the H-ADCP in each of the nine cells of the sampling volume (fig. 2) were extracted and averaged over 10-minute intervals for each event. The peak in the discharge for each event was used to separate the rising and falling limbs of each event hydrograph; all data were categorized as to belonging to either a rising or falling limb and were later combined for statistical analysis. To understand the shape of the transverse velocity profile and its evolution in time, every 10 -minute velocity profile $(n=18,094)$ was fit by using the beta density function, and $\alpha$ and $\beta$ values for each best fit were recorded and analyzed.

The observed velocity profiles for 102 events in the CSSC near Lemont are flat and generally relatively symmetric, with a slight skew to the right bank (fig. 11). With the exception of several low flow profiles, the $\alpha$ and $\beta$ values are tightly clustered between 1 and 1.75. There is no significant variation between the rising and falling limbs as the data clouds overlap. The rightward skew of the profiles is consistent with observations from November 2006 to January 2010 reported by Jackson and others (2012).

Coefficients of the beta distribution determined by using observed data show almost no change between the median values for the rising and falling limbs of the hydrograph and have only a small variation about their median values for each event (fig. 12). Statistical analysis shows that for 8,163 observations on the rising limb and 9,931 observations on the falling limb, the median values for $\alpha$ for both limbs are 1.21 and the median values for $\beta$ are 1.3 and 1.29 for the rising and falling limbs, respectively. Over each event, both $\alpha$ and $\beta$ showed the greatest variance at low flows; and as the flow increased, the values of $\alpha$ and $\beta$ decreased towards flatter profiles and coefficients just above unity (fig. 12 inset). Statistically, $\beta$ showed slightly more variation over each event than $\alpha$ : the median values of the standard deviation of $\beta$ were 0.07 and 0.083 for the rising and falling limbs, respectively, whereas the median values of the standard deviation of $\alpha$ were 0.056 and 0.067 for the rising and falling limbs, respectively. The slightly greater variability in $\beta$ indicates the potential for increased asymmetry in the flow with the skew favoring the right bank.

Several points concerning these observations are notable. First, the coefficients are nearly equal for the rising and falling limbs of the hydrograph, suggesting that there is little change in the shape of the transverse velocity profile between the rising and falling limbs of a high-flow event. In the previous section we examined a worst-case type scenario in which the coefficients varied greatly between the rising and falling limbs of the hydrograph in order to generate hysteresis. The second important point is that although $\alpha$ and $\beta$ have similar median 

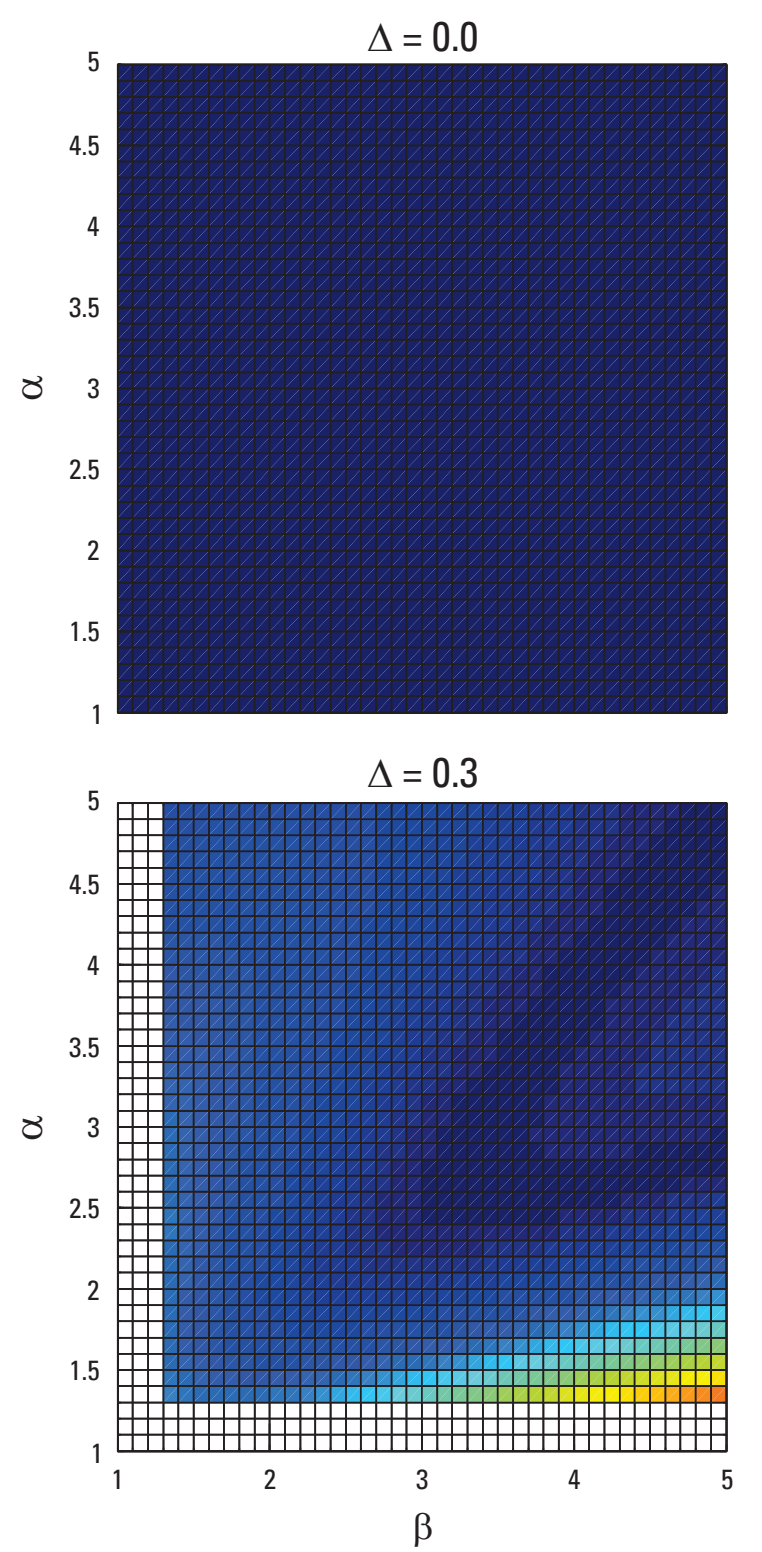

$\Delta=0.1$

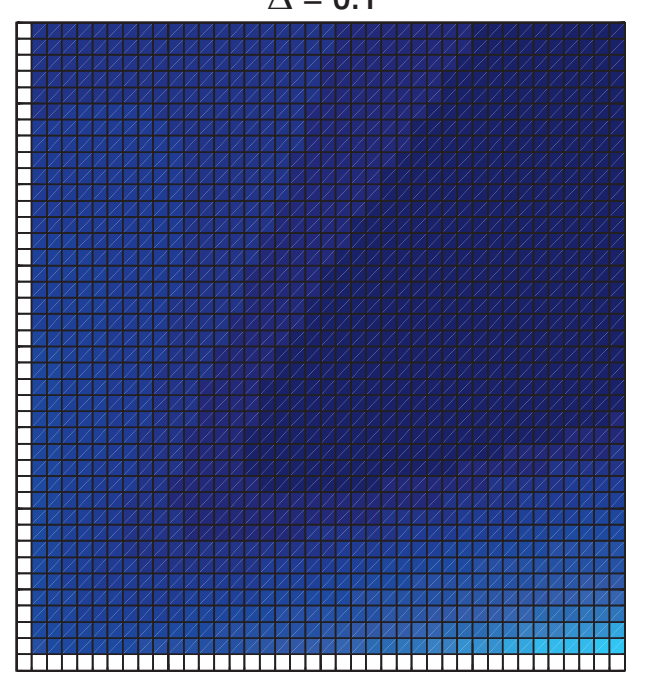

$\Delta=0.4$

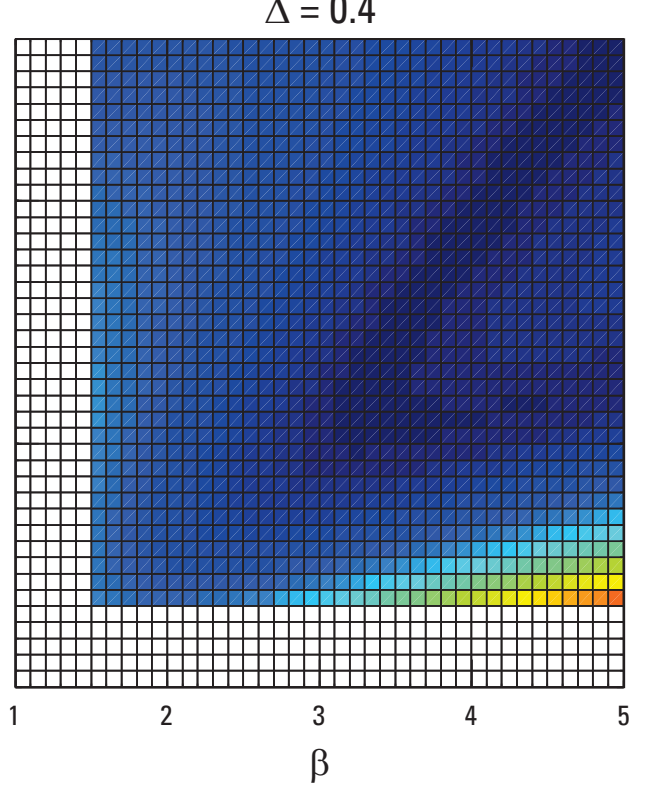

$\Delta=0.2$

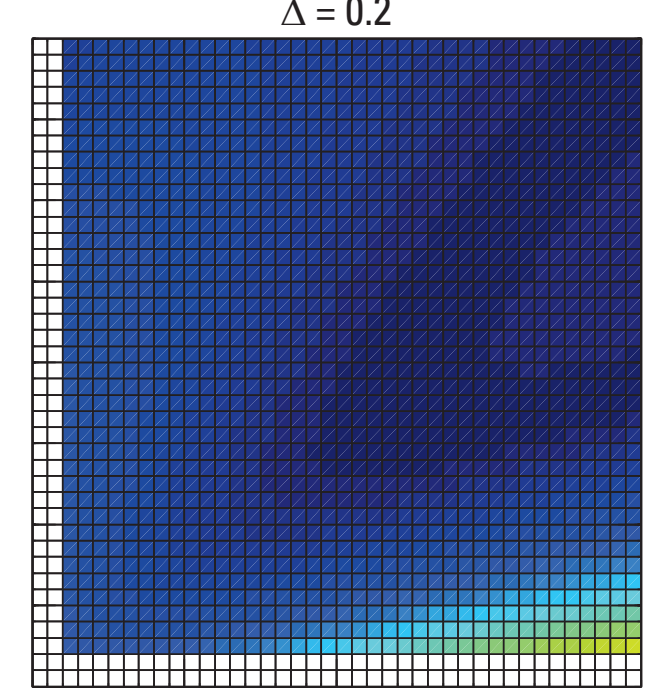

$\Delta=0.5$

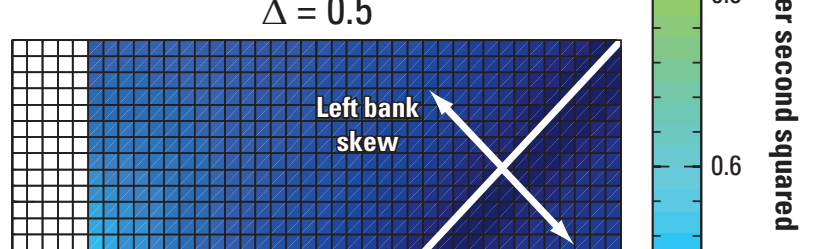

Figure 9. Six-panel plot showing the sensitivity of a five-cell, right-half with blanking zone sampling configuration to various distributions of the transverse velocity profile over a typical high-flow event. The flow profile is defined by the beta density function using coefficients $\alpha$ and $\beta, \Delta$ specifies the overall change in $\alpha$ and $\beta$ over the event, and hysteresis is quantified by using the loop area. Simulations in which either $\alpha$ and $\beta$ fall below unity are omitted from analysis because inverted profiles are not likely to occur in nature. 


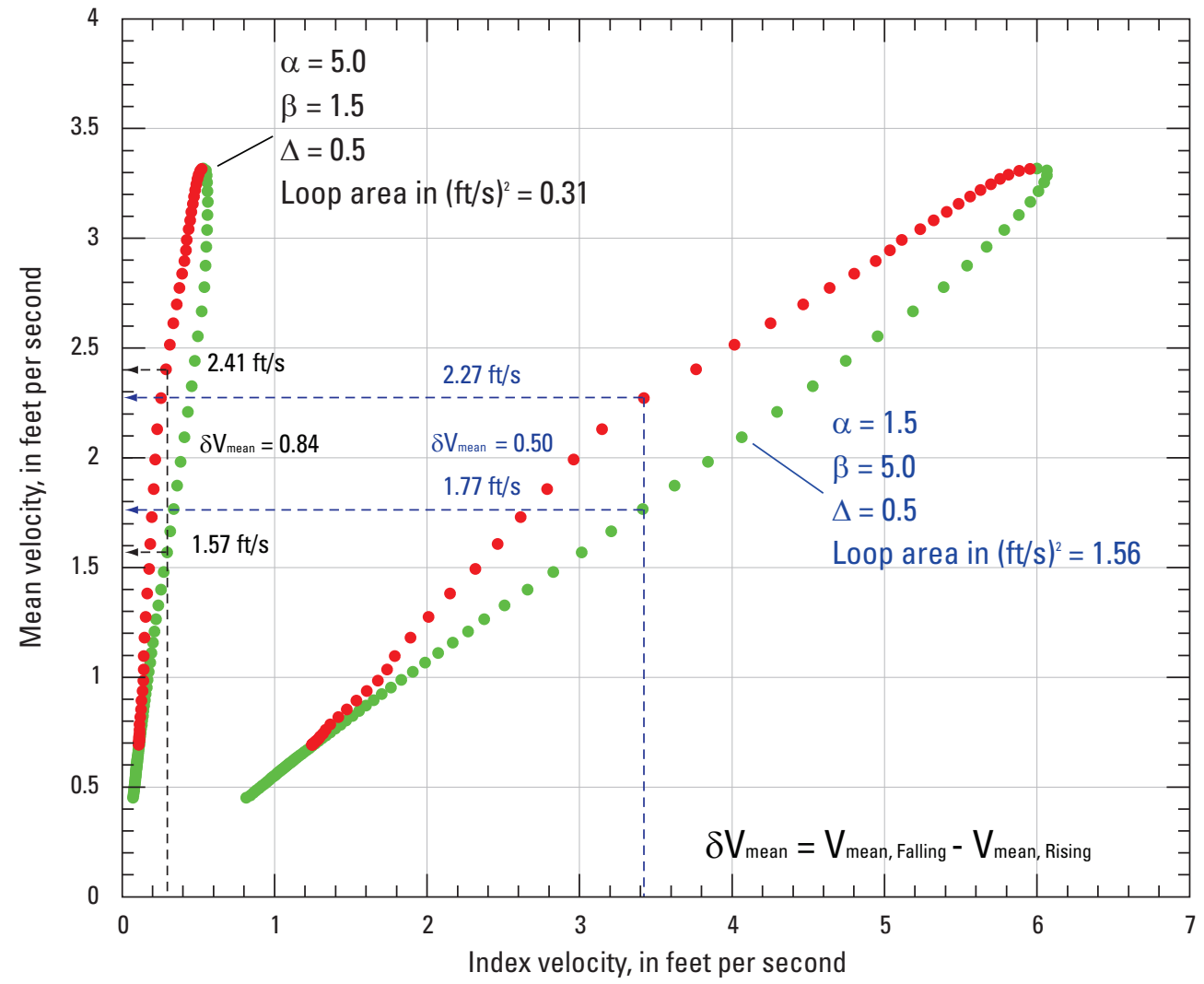

Figure 10. Index-velocity rating curves for two cases with highly skewed flow and a five-cell, right-half with blanking zone sampling configuration. Beta function parameters are shown along with the difference in mean velocity predicted by each rating curve for a given index velocity.

Figure 11. Distribution of $\alpha$ and $\beta$ for observations from 102 high-flow events in the Chicago Sanitary and Ship Canal near Lemont, Illinois. Points denote observations on the rising limb of the hydrograph, whereas open circles denote observations on the falling limb. Each event was assigned a different color to help distinguish events from one another.

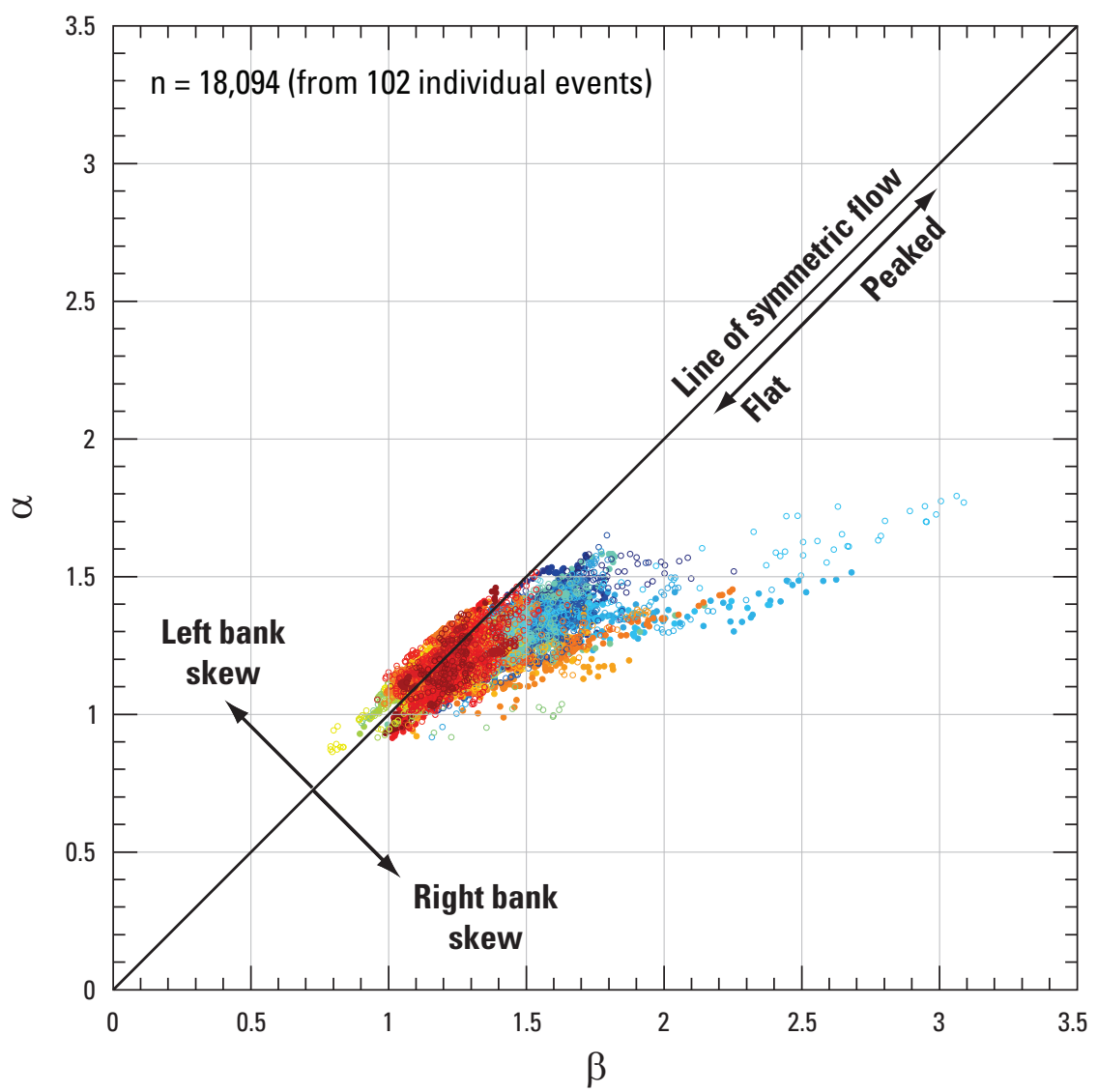



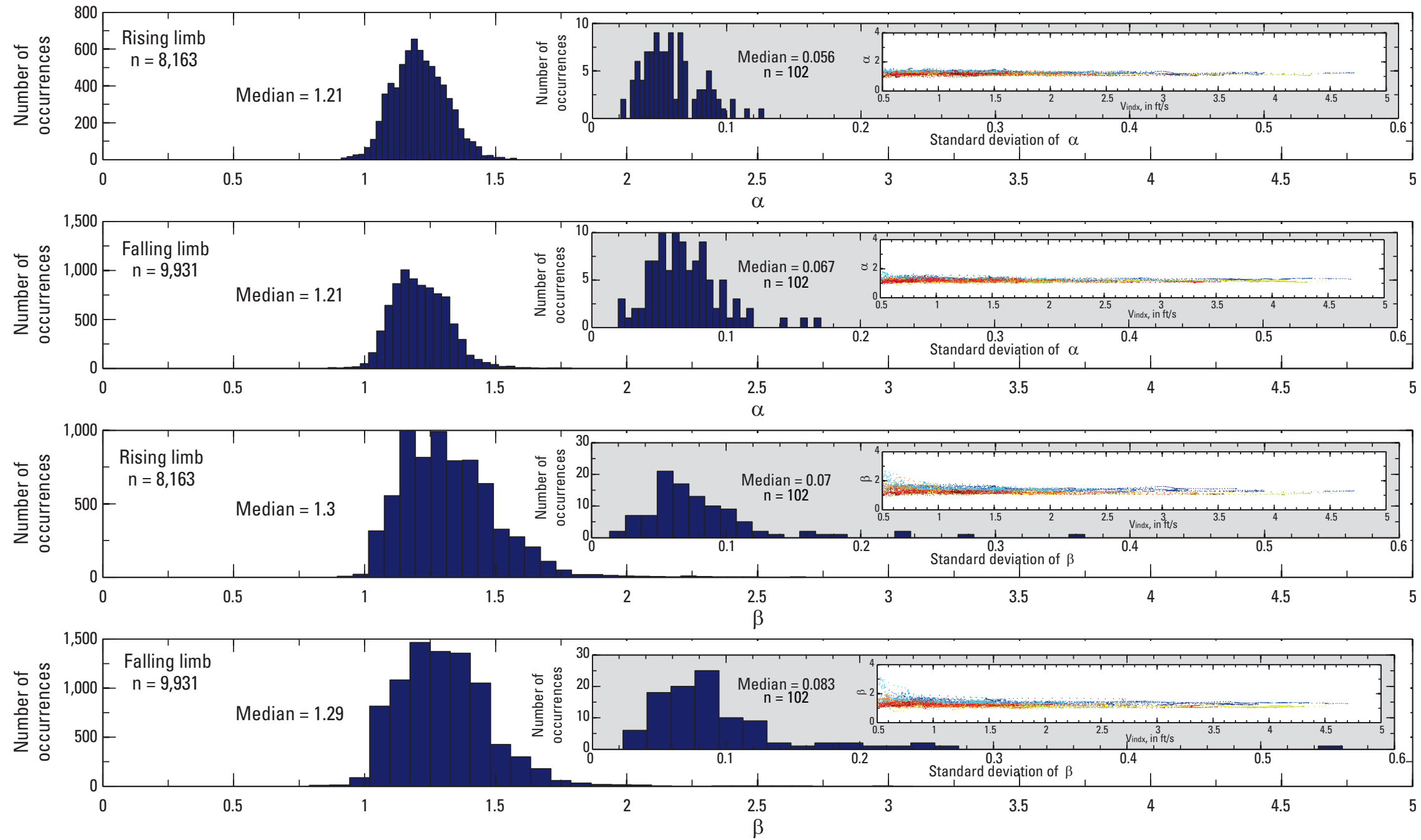

Figure 12. Histograms of $\alpha$ and $\beta$ for observations from 102 high-flow events in the Chicago Sanitary and Ship Canal near Lemont, Illinois. Inset figures show the histograms of the standard deviation of the coefficients over each event and the variation in the coefficient with velocity (color coded by event). Statistics are presented for the rising and falling limbs separately. 
values for the rising and falling limbs of the hydrograph, the coefficients do vary about these median values over each limb and cannot be considered to be constant. Therefore, $\Delta$ cannot be assumed to be equal to zero. The observed standard deviations in $\alpha$ and $\beta$ equate to a $\Delta$ value of approximately 0.2 . This was determined by using an empirical relation derived between the prescribed variation in $\alpha$ and $\beta$ in the model (for example, fig. $4 E$ ), which is based on $\Delta$, and the computed standard deviation of the $\alpha$ and $\beta$ time series. These empirical relations are linear, with one relation for the rising limb $\left(\sigma_{\alpha, \beta}=0.2661 \Delta\right)$ and one for the falling $\operatorname{limb}\left(\sigma_{\alpha, \beta}=0.316 \Delta\right)$, where $\sigma_{\alpha, \beta}$ is the standard deviation of $\alpha$ and $\beta$. Because $\Delta$ controls the variation in both $\alpha$ and $\beta$ in the model, the relations are the same for $\alpha$ and $\beta$. The conceptual model can now be run using the median values of $\alpha$ and $\beta$ and a $\Delta$ value of 0.2 to determine whether hysteresis exists for these observed conditions.

A simulation using a modified conceptual model with the observed median values of the beta density function coefficients shows no evidence of hysteresis in the index-velocity rating (fig. 13). The conceptual model was modified slightly to reflect the fact that the median values of $\alpha$ and $\beta$ over the rising and falling limbs are equal but that they vary about the median values over each limb. Therefore, the absolute value of $d Q / d t$ was used to drive the change in $\alpha$ and $\beta$, and the initial $\alpha$ and $\beta$ values were chosen so that the overall mean values over each limb approximately matched the observed median values. The computed loop area for this configuration (H-ADCP, observed beta distribution, fig. $13 H$ ) is $0.0028 \mathrm{ft}^{2}$, suggesting that hysteresis is not significant for this configuration and that there is no substantial difference in the rating curve between the rising and falling limbs of the hydrograph (fig. 13G). Although it is possible that some high-flow events may deviate from this hydraulic configuration based on median values, the deviation should be relatively small based on the observed distributions of $\alpha$ and $\beta$, and the likelihood that such deviations will result in significant hysteresis is small.
The rating curve developed from the conceptual model using observed median values of the beta density function coefficients and the H-ADCP sampling configuration compares very closely with the index-velocity rating curve in use for the H-ADCP in the CSSC near Lemont, Ill. (fig. 14). Direct comparison of the two rating curves shows that the conceptual-model rating curve plots to the left of the fieldderived H-ADCP rating curve. This shift can be accounted for by considering the difference in velocity magnitude between the sampling elevation of the H-ADCP in the water column and the height above the bed of the depth-averaged velocity, as specified by the beta density function. The H-ADCP samples the flow higher in the water column compared to the location of the mean velocity, resulting in 4.96 percent higher index velocity if one assumes a logarithmic vertical velocity profile (Jackson and others, 2012). Therefore, if one modifies the field-derived rating curve by reducing $V_{\text {indx }}$ by 5 percent over the full range of observations, the modified (shifted) rating describes the data from the conceptual model well and accounts for the left shift of the conceptual rating (fig. 14, red line). By accounting for the height of the sampling volume above the bed and using a logarithmic vertical velocity profile, we can conclude that the conceptual index-velocity rating developed by using the median observed values of the beta distribution is essentially equivalent to the field-derived rating in use for the H-ADCP in the CSSC near Lemont, Ill. It is important to note that the scatter in the rating points in the CSSC near Lemont cannot be accounted for by hysteresis in the rating curve; therefore, the scatter is likely due to uncertainties in the ADCP discharge measurements, unsteadiness in the flow over a measurement, and uncertainty in the indexvelocity measurement due to instrumentation noise and other sources of error, such as flow disturbance from vessel traffic and moored barges $0.7 \mathrm{mi}$ upstream of the gage. 

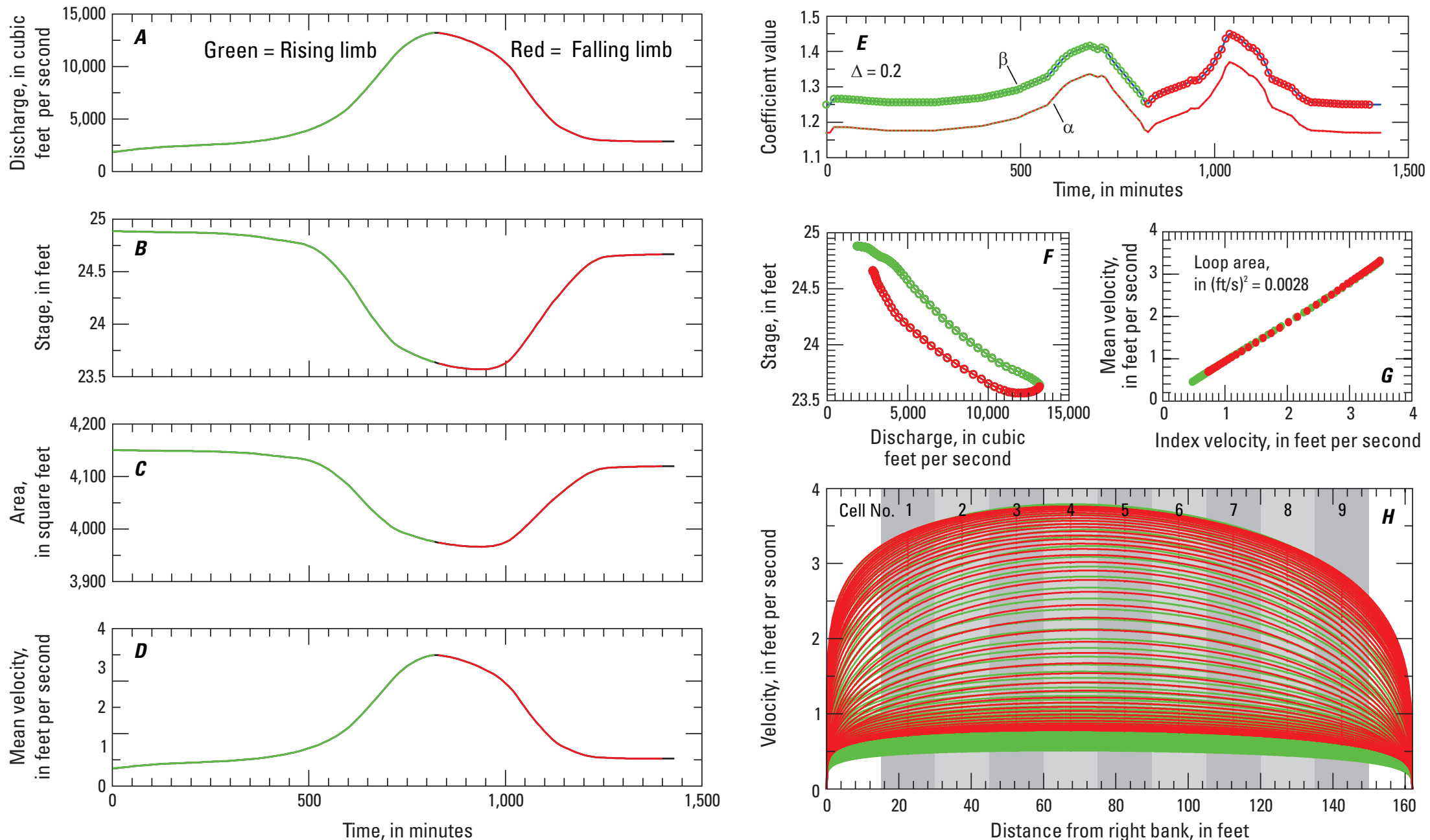

Figure 13. Compilation plot for the observed median flow distribution and the sampling configuration for the horizontal acoustic Doppler current profiler. Plots on the left: $A$, the observed hydrograph; $B$, the observed stage; $C$, the computed cross-sectional area; and $D$, the computed mean velocity. Plots on the right: $E$, the time series of beta distribution coefficients; $F$, the stage-discharge loop; $G$, the index-velocity rating; and $H$, the temporal evolution of the transverse velocity profile over the event as defined by the beta distribution. 


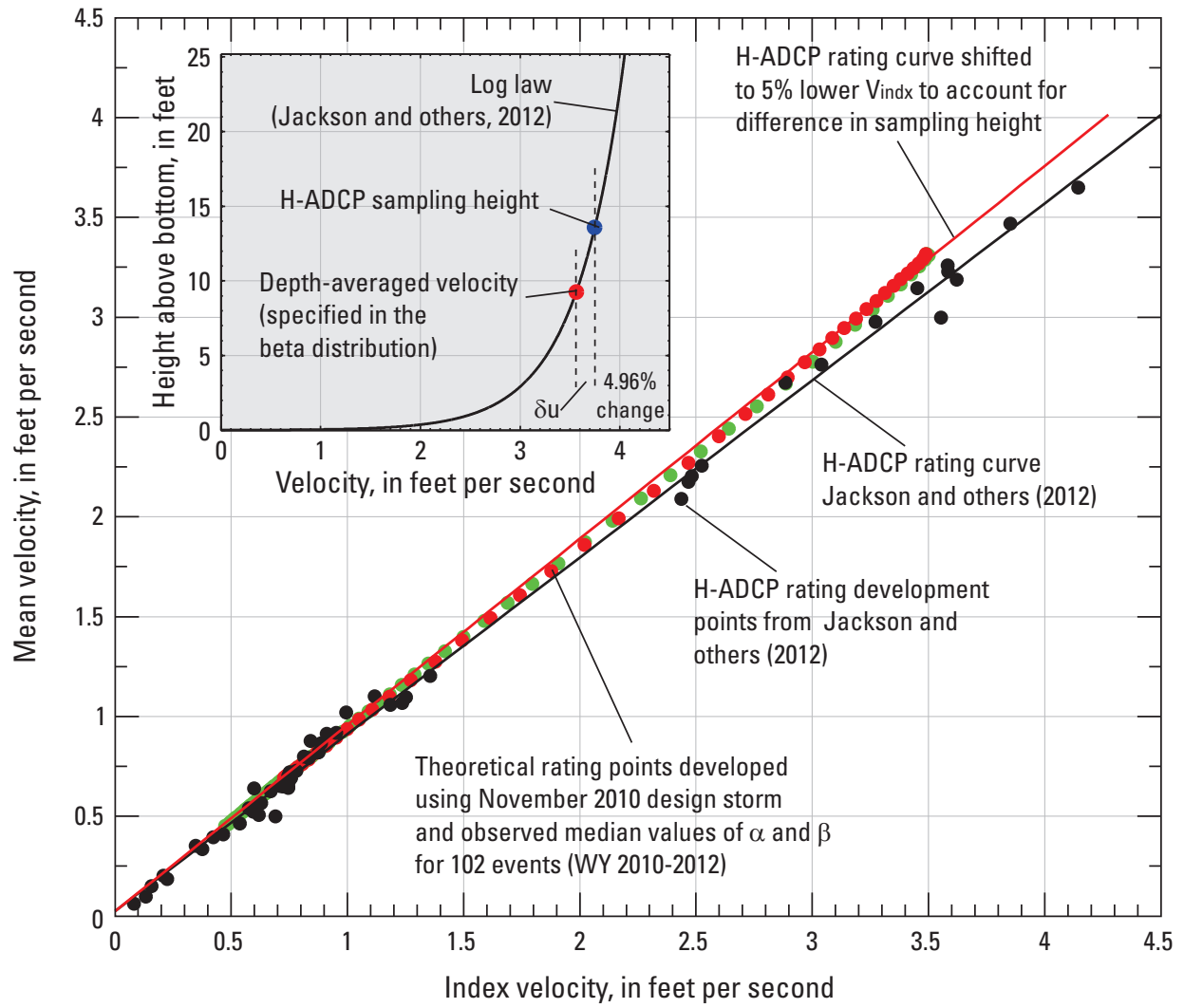

\section{EXPLANATION}

- Rising limb

- Falling limb

Figure 14. Comparison of the field-derived index-velocity rating for the horizontal acoustic Doppler current profiler (H-ADCP) in Chicago Sanitary and Ship Canal (CSSC) near Lemont, Illinois, to the conceptualmodel rating curve developed by using median values of the beta distribution coefficients from observed velocity profiles. Inset figure shows the logarithmic profile of velocity for the CSSC near Lemont (see Jackson and others, 2012), including the sampling height of the $\mathrm{H}-\mathrm{ADCP}$ relative to the height of the depth-averaged velocity as specified by the beta distribution.

\section{Numerical Modeling Analysis}

In order to further investigate the potential existence of hysteresis in the index-velocity rating for the CSSC near Lemont, a three-dimensional hydrodynamic model was applied. The computational domain for the model is shown in figure 1. A three-dimensional model was chosen for this analysis to capture flow physics in a realistic manner and to allow for inclusion of a virtual streamgage within the model, mimicking the configuration of sensors present near Lemont on the CSSC (fig. 2). The three-dimensional model was used to simulate actual high-flow events over a large range of measured boundary conditions. Additional simulations replicated the total discharge for a measured high-flow event but synthetically distributed the inflows from the CSSC and the Cal-Sag Channel over a range of scenarios in an attempt to elicit hysteresis in model-generated index-velocity ratings under a range of possible flow conditions. Index-velocity ratings were constructed by sampling the model flow field in the same manner as the field configuration of AVM and H-ADCP using virtual instruments (fig. 2). The flow events modeled as a part of this research were calibrated and validated with the help of observed water-surface-elevation and velocity data continuously measured at the USGS streamgage on the CSSC near Lemont, Ill.

\section{About the Numerical Model}

The three-dimensional numerical modeling of the aforementioned domain (fig. 1) was carried out with TELEMAC-3D (Electricité de France, 2007). The TELEMAC suite of models has been in continuous development since 1987 when the Telemac project was launched by the Research and Development department of Electricité de France. TELEMAC-3D is based on finite-element methodology (Hervouet, 2007); the numerical model solves the three-dimensional form of the shallow water equations. These governing equations consist of the continuity and momentum equations in $x$ and $y$ directions:

$$
\begin{gathered}
\frac{\partial U}{\partial x}+\frac{\partial V}{\partial y}+\frac{\partial W}{\partial z}=0 \\
\frac{\partial U}{\partial t}+U \frac{\partial U}{\partial x}+V \frac{\partial U}{\partial y}+W \frac{\partial U}{\partial z}=-g \frac{\partial Z_{s}}{\partial x}+v \Delta(U)+F_{x} \\
\frac{\partial V}{\partial t}+U \frac{\partial V}{\partial x}+V \frac{\partial V}{\partial y}+W \frac{\partial V}{\partial z}=-g \frac{\partial Z_{s}}{\partial y}+v \Delta(V)+F_{y} \\
p=p_{a t m}+\rho_{o} g\left(Z_{s}-z\right)+\rho_{o} g \int_{z}^{z_{s}} \frac{\Delta \rho}{\rho_{o}} d z
\end{gathered}
$$


In the preceding equations, $t$ is time in seconds, $U, V$ and $W$ are velocity in $x, y$ and $z$ directions, respectively, $Z_{s}$ denotes the water-surface elevation, $p$ is the pressure, $g$ is the acceleration due to gravity, $v$ is the turbulent eddy viscosity, $\rho_{o}$ is the reference density, and $F_{x}$ and $F_{y}$ denote the source terms which represent the effect of wind, Coriolis force, and the bottom friction or any other process modeled in a similar manner. The governing equations (eqs 4-7) behind the computational kernel of the model are based on the following inherent assumptions:

1. Variation of density in the conservation of mass (continuity equation) is ignored, hence it represents incompressible flow.

2. Pressure is assumed to be hydrostatic along the water column, which implies that the pressure at any given depth is the sum of the air pressure at the fluid surface plus the weight of the overlying water body.

3. Boussinesq approximation for the momentum is assumed, which implies that the density variation is considered only in the gravity term.

The numerical solution of the governing equations 4-7 is achieved by what is commonly known as the fractional step algorithm. The tremendous advantage and accuracy of the fractional step algorithm lies in the fact that the best and most highly accurate numerical schemes can be employed to solve different parts of the governing equations in a piecewise manner.

The computational algorithm of TELEMAC-3D splits the governing equations into three distinct numerical steps. In the first step, only the advection component of the governing equations is solved, using method of characteristics (Hervouet, 2007). These advected velocities are then used in the second step, where both diffusion and the source component of equations are solved by using the finite element methodology. The water depth is computed from the vertical integration of the continuity and momentum equations and includes only the pressure-continuity terms. The new computed depth enables the computation of the new free surface. To account for a continually changing model domain due to variation of the free surface, TELEMAC-3D utilizes a sigma transformation (Hervouet, 2007). Finally, the vertical velocity $(W)$ is also computed with the continuity equation. Conventional numerical modeling of riverine systems is accomplished by using a one-dimensional model (for example, HEC-RAS); but with advancements made in the field of parallel computing and easily accessible computational resources, three-dimensional modeling is becoming more common.

One of the main advantages of TELEMAC-3D is the ability to scale up on cluster computers and minimize the computational time and resources spent on different simulations. TELEMAC-3D has been parallelized by using MPI (Message Passing Interface) paradigm (Hervouet, 2007). The TELEMAC suite of models are completely open source and freely available from www.opentelemac.org.
The aforementioned three-dimensional numerical model was compiled and configured on Newton Cluster available at the Ven Te Chow Hydrosystems Lab at the University of Illinois at Urbana-Champaign (UIUC). The Newton Cluster is a 7-node, 56-core Intel Xeon cluster. Each node has 8 cores and $32 \mathrm{~GB}$ of RAM. The nodes are connected to each other with an Ethernet interconnect and share a network file system (NFS). Running the simulations on the Newton Cluster using MPI parallelization dramatically reduced the computational time required for each simulation.

\section{Model Development}

This section is dedicated to a discussion of the methods used to define the boundary conditions for the simulations, the development of the computational mesh, and the calibration and validation of the model using observed water-surface elevation data and discharge in the CSSC near Lemont, Ill.

\section{Simulated Events}

As shown in figure 1, the computational domain extends from USGS streamgage 05536995 on the downstream end to $4.35 \mathrm{mi}(7 \mathrm{~km})$ upstream of Sag Junction (the confluence of the CSSC and Cal-Sag Channel) on both CSSC and Cal-Sag Channel. Boundary conditions were imposed at these three boundaries in order to drive the model. The choice of USGS streamgage 05536995 as the endpoint of the computational domain was facilitated by the fact that the USGS has records of water-surface elevation corresponding to various flow events modeled at this location. Boundary conditions for the numerical model consisted of inflow hydrographs at the upstream boundaries of the CSSC and Cal-Sag Channel and time series of the water-surface elevation at the downstream end at Romeoville (fig. 15).

In order to simulate a range of possible flow conditions for the CSSC near Lemont, Ill., the model simulations were separated into two groups based on the imposed boundary conditions (see table 2). In the first group of simulations, a large event (peak discharge of 18,984 ft $\mathrm{ft}^{3} / \mathrm{s}$ ) from July 2010 was used as the design event (compare with other large events in table 1). To define the discharge time series in the CSSC and Cal-Sag Channel (upstream boundary conditions), the observed discharge in the CSSC near Lemont was divided several ways in order to generate a number of scenarios, but always ensuring that the contributions from the CSSC and Cal-Sag Channel summed to the observed discharge in the $\mathrm{CSSC}$ near Lemont. Estimating the inflow from the Cal-Sag Channel is necessary because there are no gage data for the Cal-Sag Channel during this time period. In all cases, the CalSag Channel contribution to the total discharge in the CSSC near Lemont during low flows was kept constant at 25 percent (estimated from discharges from the primary wastewater outfalls in the system, which make up most of the flow in the canal during low flows). During high flows, the discharge in 


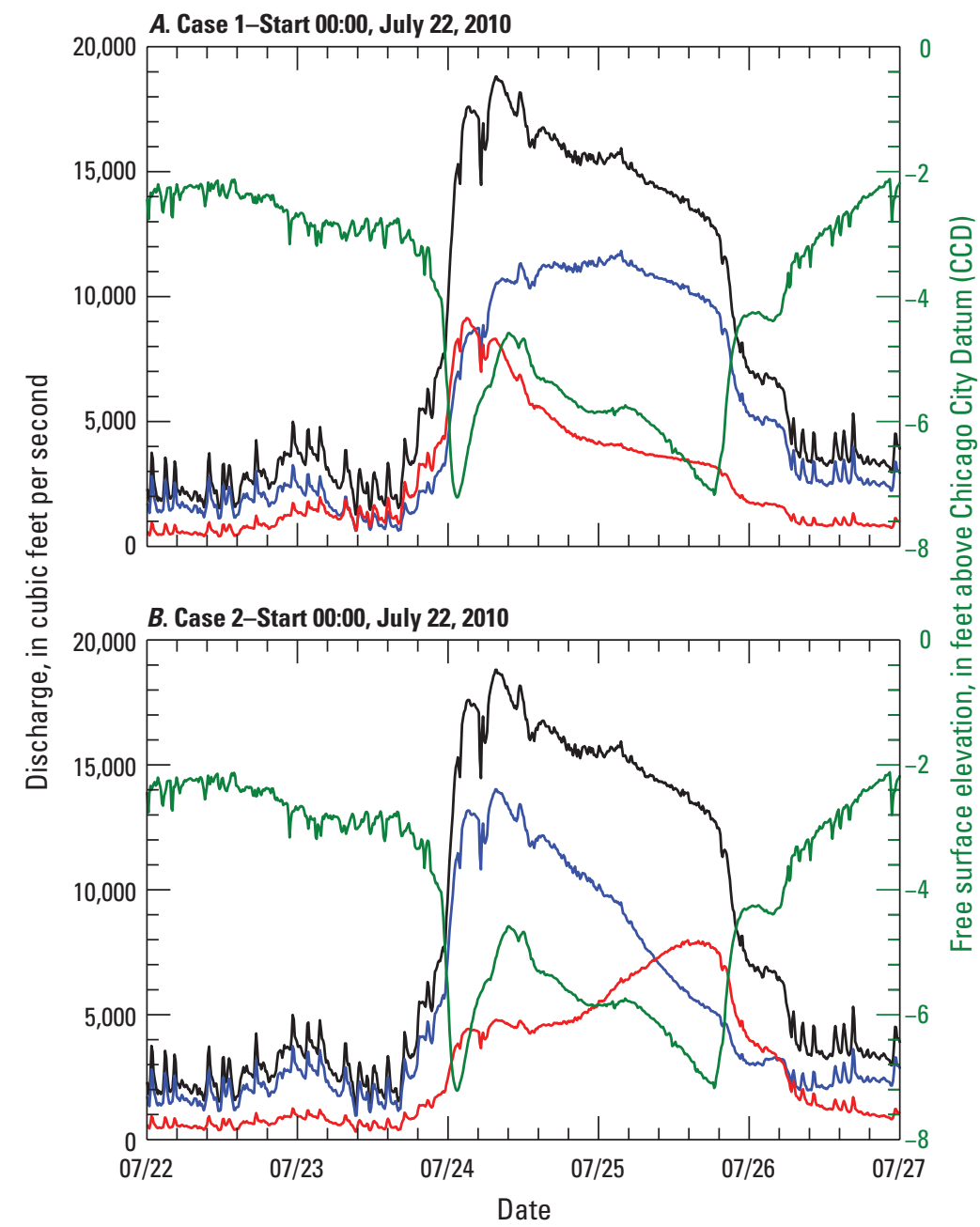

\section{EXPLANATION}

Discharge in the Chicago Sanitary and Ship Canal near Lemont, III. (05536890)

Discharge in the Cal-Sag Channel near Rt 83

Discharge in the Chicago Sanitary and Ship Canal upstream of the Junction with the Cal-Sag Channel Water-surface elevation in the Chicago Sanitary and Ship Canal at Romeoville, III. (05536995)

Figure 15. Synthetic hydrographs for the Chicago Sanitary and Ship Canal (CSSC) and Cal-Sag Channel upstream of Sag Junction and measured discharge in the CSSC at Lemont and free surface elevation in the CSSC at Romeoville Road corresponding to case 1 and case 2. Water-surface elevations are referenced to the Chicago City Datum (CCD; 0.0 feet CCD corresponds to 579.48 feet NGVD 1929). 
Table 2. Simulated high-flow events in the Chicago Sanitary and Ship Canal near Lemont, Illinois.

\begin{tabular}{|c|c|c|c|c|c|}
\hline Group & $\begin{array}{l}\text { Case/ } \\
\text { Event }\end{array}$ & $\begin{array}{l}\text { Duration, } \\
\text { in hours }\end{array}$ & Start time (CST) & $\begin{array}{c}\text { Peak discharge, } \\
\text { in cubic feet per } \\
\text { second }\end{array}$ & $\begin{array}{c}\text { Synthetic flow } \\
\text { partitioning? }\end{array}$ \\
\hline \multirow[t]{2}{*}{ Group 1} & Case 1 & 120 & 00:00 July 22, 2010 & 18,984 & Yes \\
\hline & Case 2 & 120 & 00:00 July 22, 2010 & 18,984 & Yes \\
\hline \multirow[t]{4}{*}{ Group 2} & Event 1 & 72 & 12:00 July 17,2012 & 12,697 & No \\
\hline & Event 2 & 102 & 15:00 August 24, 2012 & 13,366 & No \\
\hline & Event 3 & 23 & 22:00 July 23,2012 & 8,706 & No \\
\hline & Event 4 & 33 & 23:00 August 3, 2012 & 7,237 & No \\
\hline
\end{tabular}

the Cal-Sag Channel was computed by modeling its percent contribution to the total flow in the CSSC near Lemont as a skew-normal distribution. Adjustment of the distribution parameters (peak, variance, skewness) allowed different CalSag Channel inflow scenarios to be defined. In case 1, the contribution from the Cal-Sag Channel was allowed to peak with a maximum contribution of $9,140 \mathrm{ft}^{3} / \mathrm{s}$ before the peak of the hydrograph of the CSSC near Lemont (fig. 15A). Case 2 was chosen to allow the Cal-Sag Channel to peak later than the CSSC near Lemont, with a maximum discharge of 7,980 $\mathrm{ft}^{3} / \mathrm{s}$ (fig. 15B). The reasoning behind these cases was to determine whether any hysteresis in the index-velocity rating for the CSSC near Lemont is sensitive to the timing of the peak of the hydrograph of the Cal-Sag Channel relative to the peak in the CSSC. For both cases, the peak discharge from the Cal-Sag Channel was defined as 60 percent of the total flow in the CSSC at Lemont, Ill. A peak contribution of 60 percent from the Cal-Sag Channel was chosen to represent an event that presented a potential for hysteresis because the Cal-Sag Channel and CSSC inflows would peak on opposite limbs of the hydrograph at Lemont and the Cal-Sag Channel inflow would briefly dominate the flow distribution, possibly leading to skewing of the velocity profile in the CSSC at Lemont and hysteresis. In addition, simulations with the peak Cal-Sag Channel contribution of 40 percent and 80 percent of the total flow in the CSSC at Lemont, Ill. were tested but are not presented in this report because they yielded no additional information.

In the second group of simulations, four different highflow events of varying peak discharge and time duration were simulated (fig. 16). All four events utilized measured discharge on the CSSC and Cal-Sag Channel for upstream boundary conditions, so no synthetic flow distributions were required due to the installation of the USGS streamgage on the Cal-Sag Channel near Route 83 (05536700) in 2011. The four different flow events simulated are hereafter called event 1 , event 2 , event 3, and event 4 (fig. 16). The timing and characteristics of each of the four events are given in table 2. Discharge from the CSSC and Cal-Sag Channel are shown for the four events in figure 16.

\section{The Computational Mesh}

The computational mesh of the model was developed by using high-resolution bathymetric data provided by the U.S. Army Corps of Engineers, the USGS, and the University of Illinois. As shown in figure 17, the computational mesh consists of 21,000 nodal points and 36,000 triangular elements with 8 layers in vertical. TELEMAC-3D works in conjunction with an unstructured mesh. The use of an unstructured mesh tremendously reduces the preprocessing time required for the model setup and offers homogeneous mesh resolution in the entire domain. The advantage of using unstructured mesh becomes even more critical in the zone of the confluence. Because of the flexibility offered by the use of unstructured mesh, it was possible to keep the mesh resolution constant at a 4-m edge length throughout the modeled domain.

\section{Model Calibration and Validation}

The model was calibrated and the results were validated by using water-surface elevation records measured in the CSSC near Lemont (05536890). TELEMAC-3D provides the facility of splitting the turbulent eddy viscosity in horizontal and vertical components. Turbulence modeling can be accomplished through a variety of models. At the simplest level, eddy viscosity can be assigned a constant value throughout the domain and can be used as a calibration parameter. Such an assigned value has definite impact on size and shape of recirculation zones and eddy structures present in the flow being modeled. At a more complex level, the turbulence modeling is done through second-order model; for example, a $\kappa-\varepsilon$ model (Wilcox, 2004). In the present simulations, the turbulence modeling in the horizontal direction was achieved by assigning a constant eddy viscosity of $0.001 \mathrm{~m}^{2} / \mathrm{s}$, which is reasonable compared with published values. Turbulence modeling in the vertical direction used a Prandtl's mixing length model (Wilcox, 2004), where the vertical eddy viscosity is a function of mean velocity gradient. Prandtl's mixing length model for specifying the vertical eddy viscosity is especially suitable for 


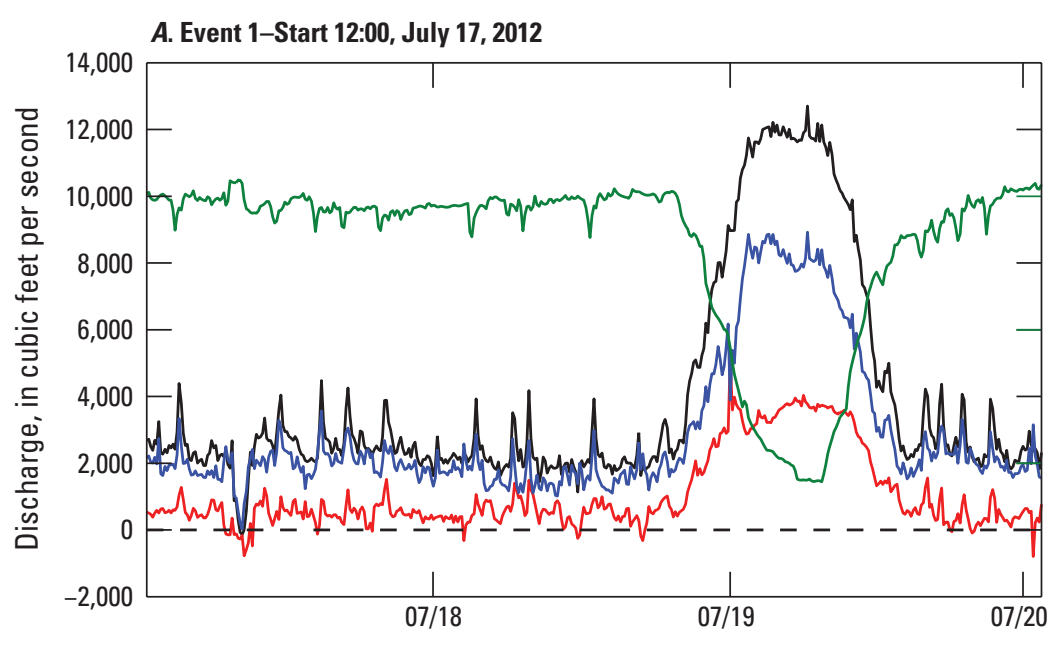

B. Event 2-Start 15:00, August 24, 2012
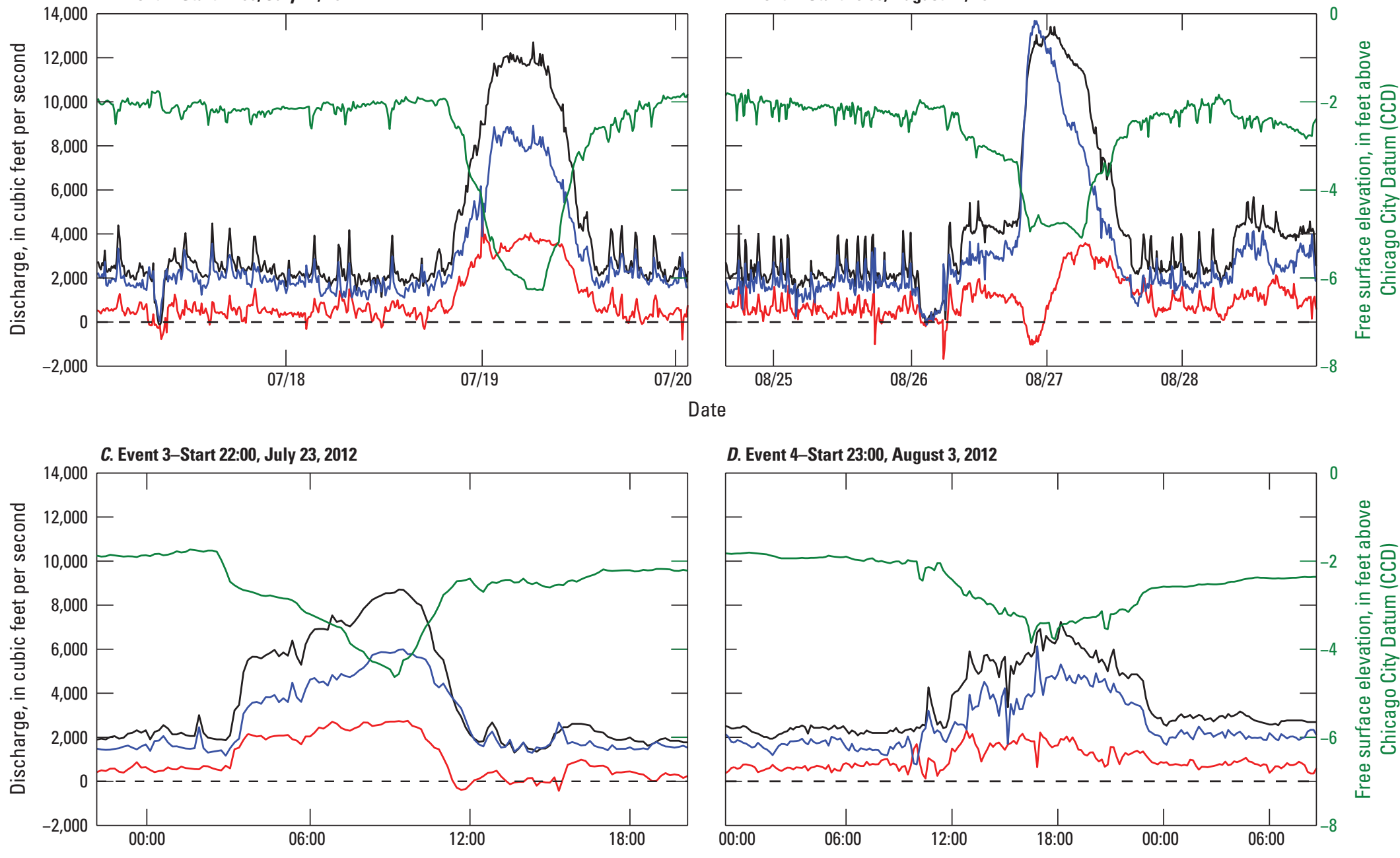

D. Event 4-Start 23:00, August 3, 2012

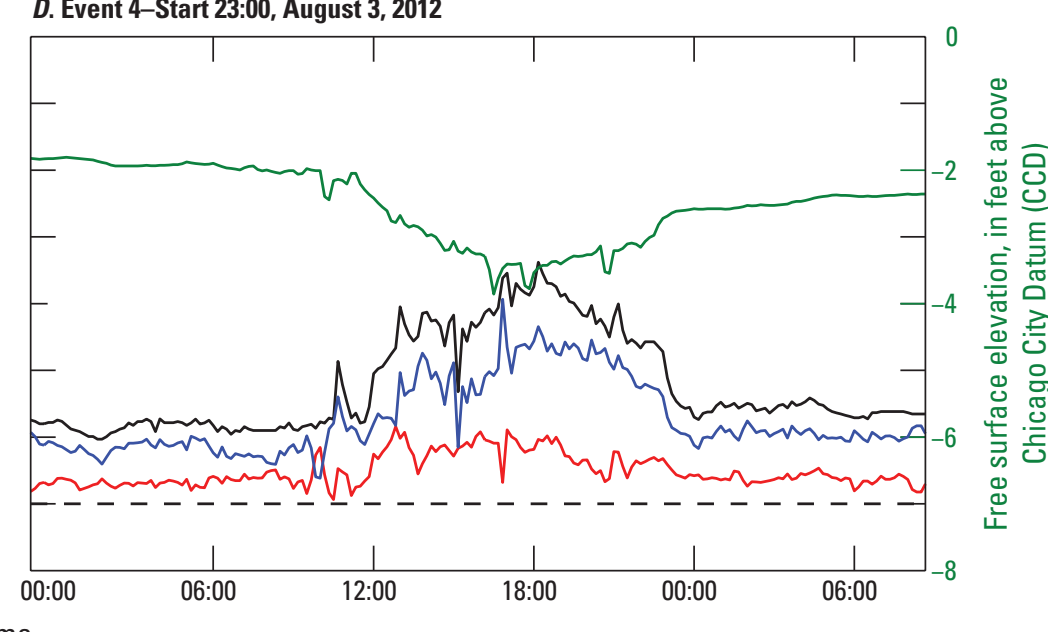

\section{EXPLANATION}

- Discharge in the Chicago Sanitary and Ship Canal near Lemont, III. (05536890)

Discharge in the Cal-Sag Channel near Rt 83 (05536700)

Discharge in the Chicago Sanitary and Ship Canal upstream of the Junction with the Cal-Sag Channel

Water-surface elevation in the Chicago Sanitary and Ship Canal at Romeoville, III. (05536995)

Figure 16. Measured hydrographs for the Chicago Sanitary and Ship Canal (CSSC) and Cal-Sag Channel and water-surface elevation in the CSSC at Romeoville Road corresponding to event 1 , event 2 , event 3 , and event 4 . 


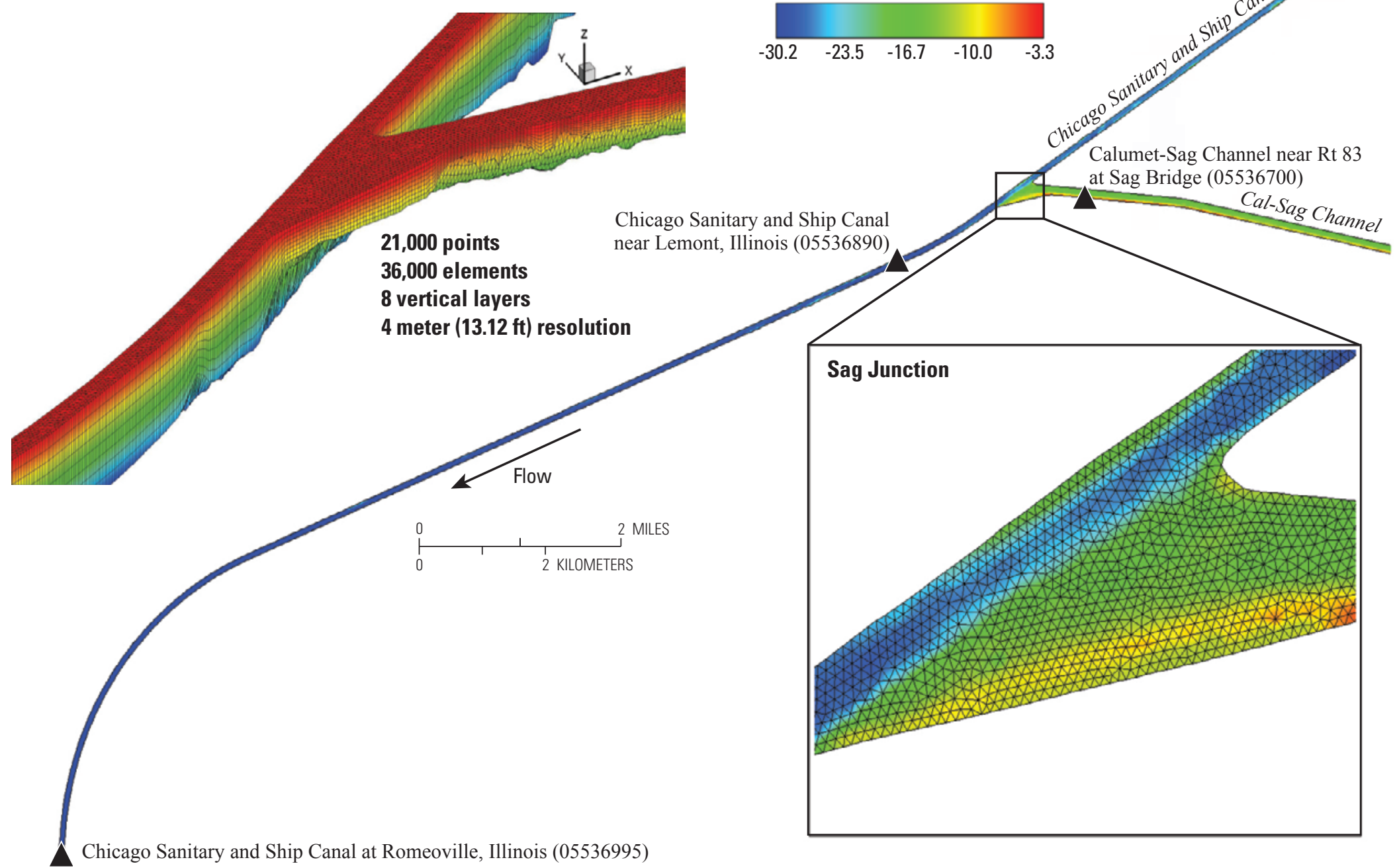

Bed elevation, in feet above Chicago City Datum (CCD)

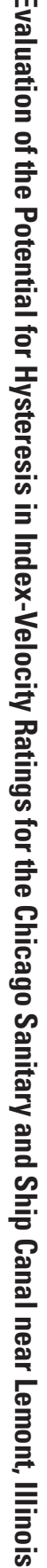

Figure 17. Top view and three-dimensional view of the computational mesh for the modeled domain. 
flows with a high degree of free-surface variation, which is the case during high flow through the CSSC. The vertical eddy viscosity, $v$, for the Prandtl's mixing length model is given by

$$
v=L_{m}^{2} \sqrt{2 D_{i j} D_{i j}}
$$

where $D_{i j}=\frac{1}{2}\left(\frac{\delta \bar{U}_{i}}{\delta x_{j}}+\frac{\delta \bar{U}_{j}}{\delta x_{i}}\right)$ and $L_{m}$ is the mixing length.

The mixing length $\left(L_{m}\right)$ in equation 8 is the proportionality constant between the eddy viscosity and mean velocity gradient. Physically, the mixing length is the distance traversed by a mass of fluid before it becomes blended in with neighboring masses (Prandtl, 1926). The version of Prandtl's mixing length model presented in this simulation is a standard one, where $L_{m}$ is determined by an empirical relationship between the water depth $(H)$ and the distance from the bed (z). In this standard mixing length model, $L_{m}$ is 0 at the bed $(z=0)$, increases linearly to $L_{m}=0.08 \mathrm{H}$ at $z=0.2 \mathrm{H}$ and is held constant at $L_{m}=0.08 H$ for $z>0.2 H$ (Hervouet, 2007). Another parameter that was adjusted during the calibration procedure was Manning's roughness, which corresponds to the bottom roughness and is modeled as a part of the momentum equations. Both the calibration parameters (that is, Manning's roughness and horizontal eddy viscosity) were calibrated to capture the water-surface elevation variation observed at the validation point near Lemont (USGS gage 05536890) (fig. 1). The best match between the observed and simulated water-surface elevation for the CSSC near Lemont was obtained with Manning's $n$ value of 0.0358 and horizontal eddy viscosity of $0.001 \mathrm{~m}^{2} / \mathrm{s}$.

The model was calibrated and validated with the watersurface elevation data recorded for the CSSC at the USGS streamgage near Lemont, Ill. (05536850). Cases 1 and 2 were primarily used for calibration of the model and events $1-4$ and additional synthetic cases (not shown) served as validation data. The comparative plot between observed and simulated free-surface elevations corresponding to all synthetic cases and measured events is presented in figure 18. The model captures the free-surface variation in the CSSC near Lemont in a satisfactory manner. For example, during event 1 (fig. 18C) the match between the simulated and observed free surface is especially good after the drawdown starts, 42 hours after the start of the simulation. Before the drawdown begins, there are number of instances when the incoming flow from Cal-Sag Channel is negative; for instance, 8 hours after the start of the simulation the inflow from Cal-Sag Channel is $-773 \mathrm{ft}^{3} / \mathrm{s}\left(-21.88 \mathrm{~m}^{3} / \mathrm{s}\right)$, indicating an upstream flow (fig. 16A). In fact, upstream flow also occurred in the main channel of the CSSC near Lemont at this same time. Flow reversals on this system are relatively common and can occur because of control changes at Lockport Lock and Dam at
Lockport, Ill., which is approximately $11.5 \mathrm{mi}$ downstream of Lemont (Jackson and others, 2012). Each lockage through the system creates a disturbance that propagates upstream, causing much of the variation in discharge at low flows. In addition, periodic shutdowns of flow through the Lockport Powerhouse for maintenance and worker safety can cause flow reversals as the disturbance propagates upstream.

Observed and simulated discharges for the CSSC near Lemont, Ill., compare well for all the simulated events (fig. 19). Some simulated discharges vary significantly from the observed values at the start of the simulation but quickly tend to match well with the observed discharge in the CSSC near Lemont. Although the simulated discharges show slightly more variability than the observed discharges, lockageinduced spikes during dry-weather flow are captured. The model slightly underpredicts the peak discharge for case 1 and case 2, but it otherwise simulates the observed discharge satisfactorily.

\section{Model Rating Development}

For each simulation of the hydrodynamic model, the model output was sampled by using a virtual streamgage and employed in developing an index-velocity rating curve for each event. The remainder of this section discusses the details of this process.

\section{Sampling the Model Output}

Modeled flow fields from each simulation were saved at 10-minute time steps for rating development during postprocessing. Each flow field consisted of three-dimensional velocity data at the resolution of the computational mesh. For each of the six simulations and every 10-minute time step within the simulation, the model output was sampled with a virtual AVM and H-ADCP. Sampling volumes of each virtual instrument matched the sampling volumes of the physical instruments deployed in the field (see fig. 2). The virtual AVM velocity sensors were located at 3 different path elevations in the water column, and velocity magnitude was extracted at 40 equidistant points along the $3 \mathrm{AVM}$ paths. The velocity magnitude corresponding to these 40 points were averaged at each AVM path elevation to get an average velocity magnitude for each path. Finally, the arithmetic mean of the average velocity magnitude at each AVM path elevation was computed to obtain the virtual AVM index velocity at each time step. The virtual H-ADCP sampled the flow field across the same nine-cell sampling volume of the field instrument, and the virtual $\mathrm{H}-\mathrm{ADCP}$ index velocity was obtained by averaging the velocity magnitude within the H-ADCP sampling volume at each time step. These index velocities from the virtual AVM and the $\mathrm{H}-\mathrm{ADCP}$ provided the abscissa values for the model index-velocity rating. 

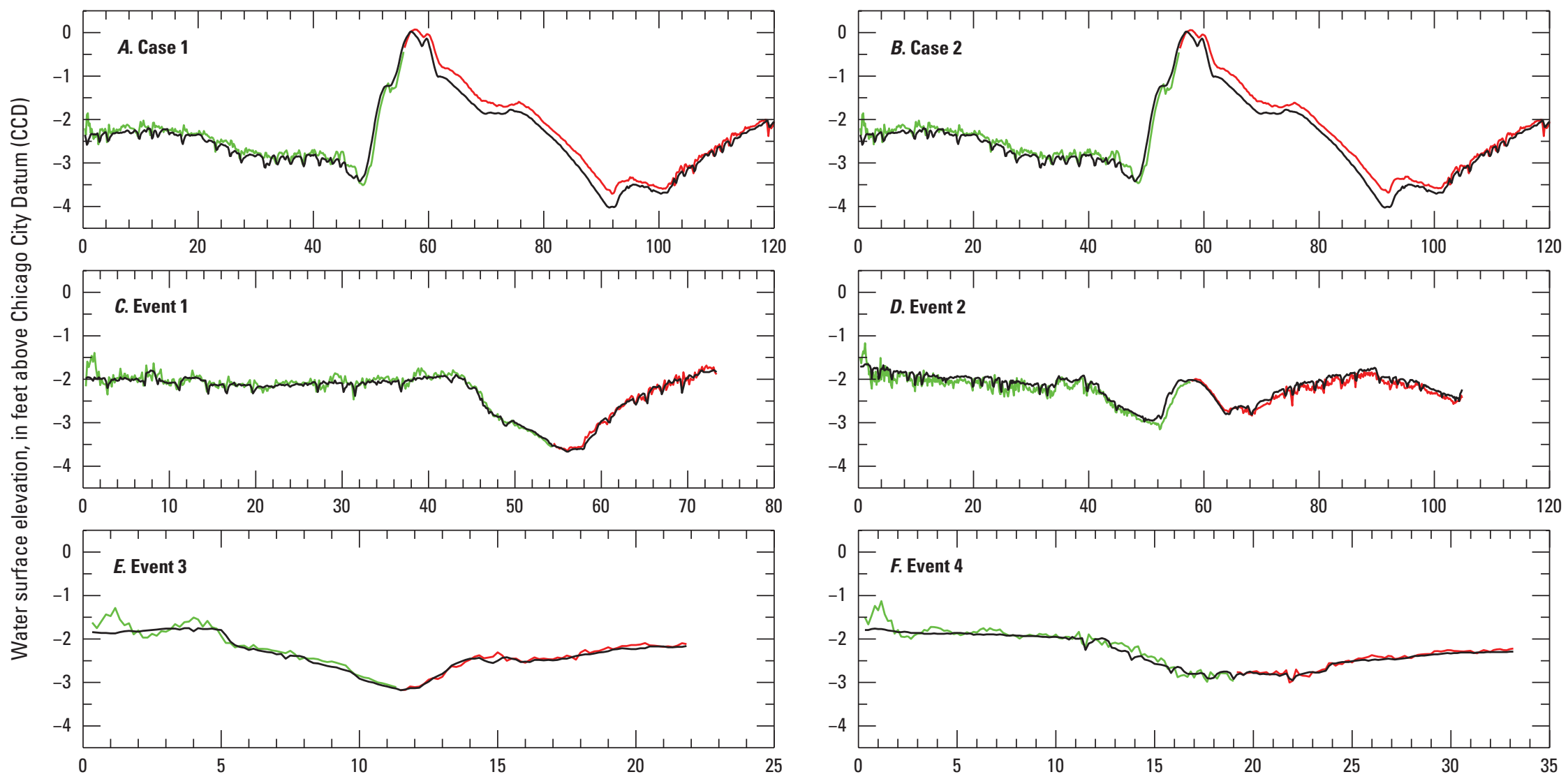

Time, in hours

\section{EXPLANATION}

Observed water-surface elevation in the Chicago Sanitary and Ship Canal near Lemont, III. (05536890)

Model water-surface elevation (rising limb)

Model water-surface elevation (falling limb)

Figure 18. Comparison between simulated and observed water-surface elevation at the USGS streamgage on the Chicago Sanitary and Ship Canal near Lemont, Illinois (05536890), corresponding to all simulated cases and observed events. 

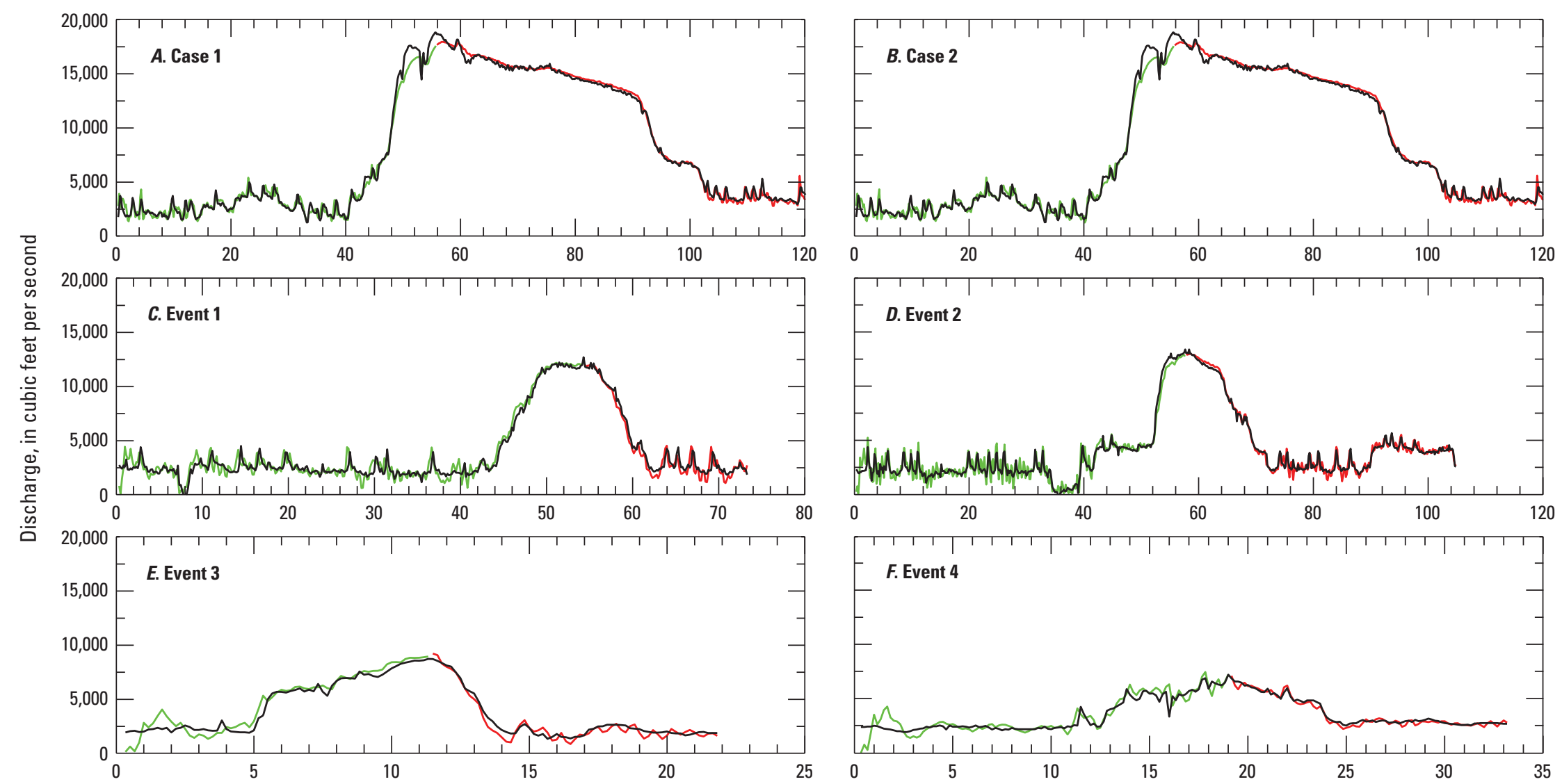

Time, in hours

\section{EXPLANATION}

Observed discharge in the Chicago Sanitary and Ship Canal near Lemont, III. (05536890)

Model discharge (rising limb)

Model discharge (falling limb)

Figure 19. Comparison between simulated and observed discharge at the USGS streamgage on the Chicago Sanitary and Ship Canal near Lemont, Illinois (05536890), corresponding to all synthetic cases and measured events. 
The ordinate values for the model index-velocity rating, $V_{\text {mean }}$ (average velocity through the section), were computed by using the 10-minute flow fields from the model sampled at the measurement section identified in figure 2 and used in the field for boat-mounted ADCP (BM-ADCP) measurements. This procedure ensures that the discharge in the model is measured at the same section as the discharge is measured in the field. The total discharge through the section was computed by multiplying the width of the BM-ADCP cross section by the mean depth-averaged specific discharge of the measurement section. The total discharge was also computed by summing the fluxes through each grid node in the measurement section, and both methods were found to give approximately the same total discharge. The virtual $V_{\text {mean }}$ was computed by dividing the total discharge at each time step by the rated cross-sectional area for that time step. The rated area was computed by using the stage-area rating for the USGS streamgage on the CSSC near Lemont (Jackson and others 2012). Differences between the area determined from the stage-area rating and the area from the model output were computed and found to be negligible.

\section{Building the Ratings}

Sampling of the model output as described in the previous section allowed computation of virtual index velocities for both instruments and a virtual mean velocity for the channel at 10-minute intervals over the duration of each simulation. Index-velocity rating curves for each simulation were generated by plotting the mean velocity for the channel $V_{\text {mean }}$ against the index velocity for each virtual instrument (figs. 20 and 21). To facilitate analysis, the rating points were color coded by points computed on the rising limb (green) and falling limb (red) of the hydrograph. Any differences in the rating points for the rising and falling limbs could introduce error into computations of discharge from an index-velocity rating, and large deviations suggest that hysteresis may occur at this site. For comparison, the field-derived rating curve and field measurements used to derive the rating are plotted on each figure, along with the residuals.

\section{Discussion}

Model-derived index-velocity ratings for all six of the simulated high flow events are in good agreement with the field-derived index-velocity ratings for the Lemont gage given by Jackson and others (2012) (figs. 20 and 21). Six events were simulated with peak discharges ranging from approximately 7,200 to $19,000 \mathrm{ft}^{3} / \mathrm{s}$, and all the model-derived indexvelocity ratings exhibit nearly identical behavior for the rising and falling limbs of the hydrograph. With the exception of the upper 10 percent of the rating for case 1 and case 2, the ratings are generally linear over the entirety of the event. Case 1 and case 2 show a slight break in the slope at high flows, and this deviation will be discussed in detail later in this section. The model-derived ratings for both instruments plot slightly to the left of the field-derived ratings for nearly all events, suggesting that index velocities in the model are slightly low compared to those computed in the field. In general, the model index velocities are lower than field values by less than $0.1 \mathrm{ft} / \mathrm{s}$ (with the exception of the upper range of the case 1 and case 2 ratings). However, the slight difference in the model and field ratings may be also attributed to the inability of the model to exactly replicate the observed stage and discharge time series over the full range of each event (figs. 18 and 19). Slight differences in discharge and stage between the model and the field observations can lead to changes in $V_{\text {mean }}$, thus affecting the rating.

No substantial hysteresis was observed in the modelderived index-velocity ratings for any of the six simulated high-flow events (figs. 20 and 21). Slight deviation between the rising- and falling-limb rating points in case 1 and case 2 at high flows can be attributed primarily to the inability of the model to accurately replicate the discharge and stage in the CSSC near Lemont during the peak of the event (figs. 18 and 19). The nearly identical ratings developed for case 1 and case 2 suggest that the timing of the contribution from the CalSag Channel with respect to the flood wave in the CSSC has little to no effect on the rating curve in the CSSC near Lemont. (As discussed previously, case 1 and case 2 were the same event but with differing synthetic flow distributions between the CSSC and Cal-Sag Channel, case 1 being early Cal-Sag Channel contribution and case 2 being late Cal-Sag Channel contribution.) Finally, the scatter in the rating points derived from field measurements is significantly larger than any observed hysteresis in the model and therefore is likely not an artifact of hysteresis in the field measurements.

The deviation in the linear trend of the ratings for case 1 and case 2 (and to a lesser extent event 2) requires more discussion. The break in the slope of the rating occurs for case 1 and case 2 at the point on the rising limb of the hydrograph when the stage-discharge relation at Romeoville (downstream boundary condition) transitions from an inversely proportional relation (higher discharge with lower stage) to a directly proportional relation (higher discharge with higher stage) (fig. 15). At this point, the stage in the canal increases in the middle of the drawdown period (a drawdown is a typical response due to anticipation of heavy precipitation to allow for storage in the canal) in response to a large influx of runoff to the canal. Stage increases because the influx of water to the canal exceeds the discharge of water through the generators and sluice gates at the Lockport Powerhouse and sluice gates at the Controlling Works upstream of Lockport. It is during this period that the stage-discharge relation transitions to one that is directly proportional (rather than inversely proportional), and the model-derived index-velocity rating changes slope. Once the stage-discharge relation transitions back to an inversely proportional relation, the model-derived rating transitions back to the original slope. This behavior can be seen in case 1 and case 2 and to a lesser extent in event 2 for both the AVM and H-ADCP. A direct comparison of the observed H-ADCP velocity data for each of the nine cells to the model output for each of the nine cells reveals that the median value 


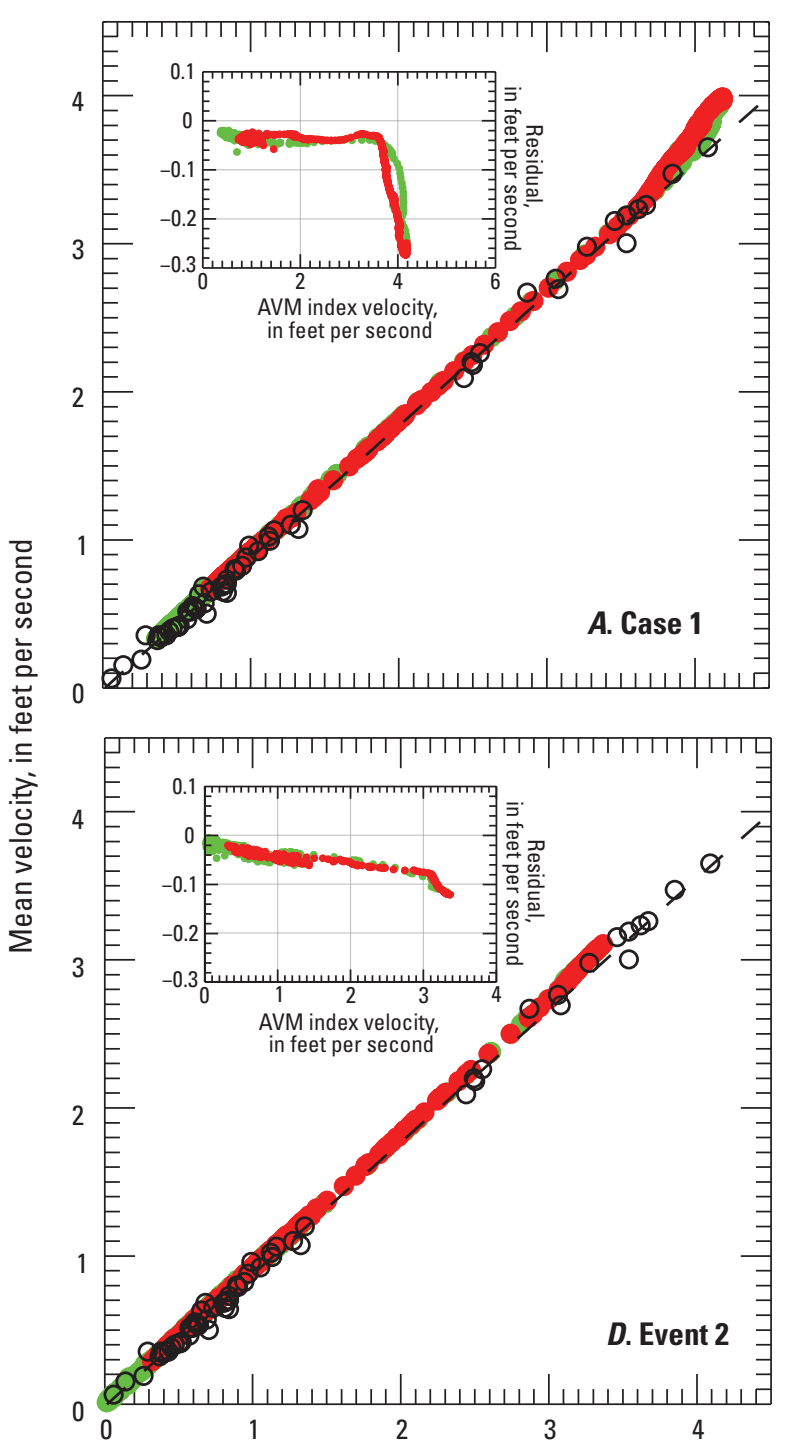

EXPLANATION

- - Field-derived rating (Jackson and others, 2012)

$\bigcirc \quad$ Field measurement (Jackson and others, 2012)

- Model rating point (rising limb)

- Model rating point (falling limb)
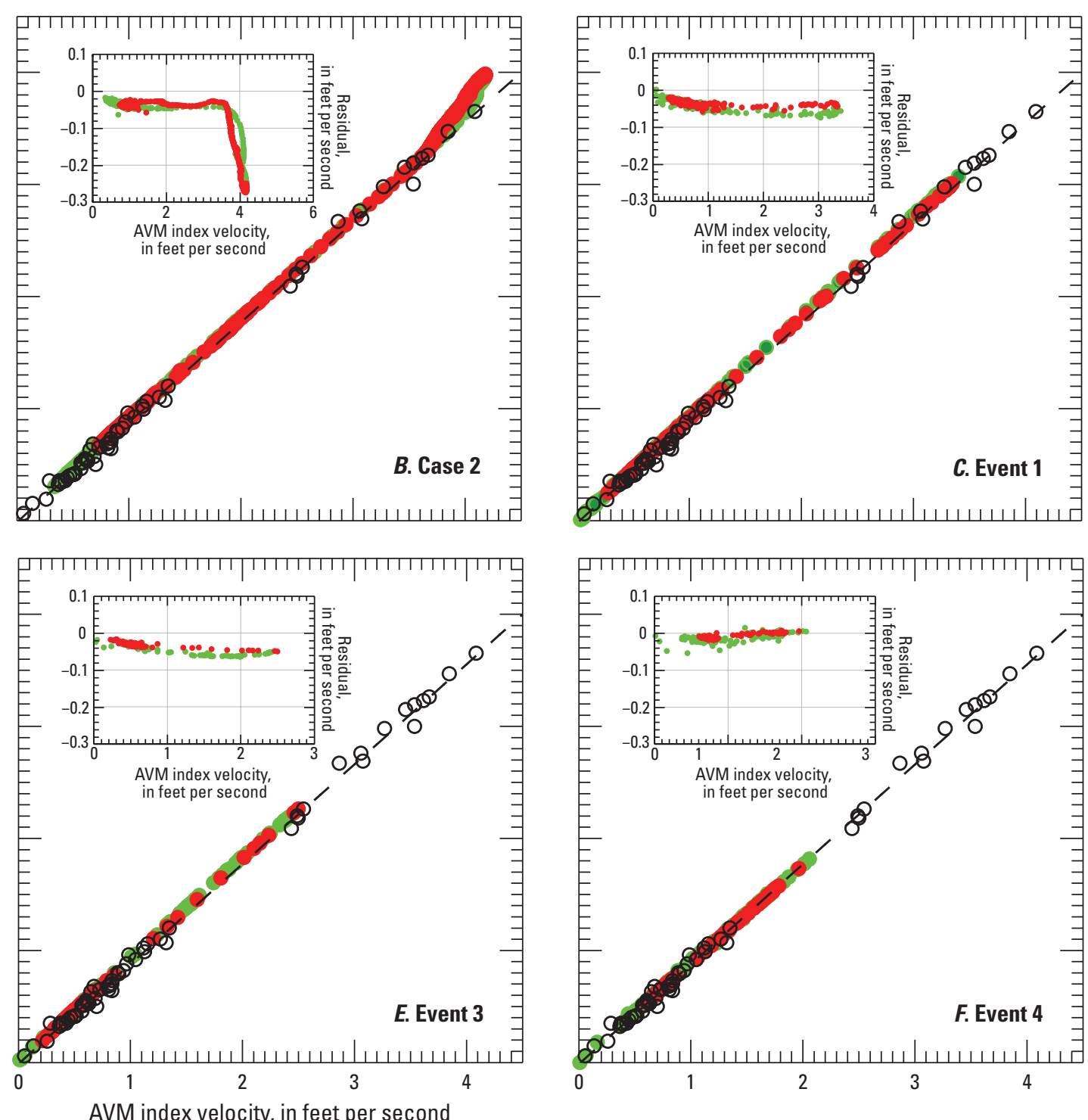

AVM index velocity, in feet per second

Figure 20. Model-derived index-velocity rating curves corresponding to the acoustic velocity meter (AVM) sensor configuration for all simulated cases and events. The field-derived indexvelocity rating for the AVM is shown for reference, along with residuals comparing the model and field rating curves (residual $=V_{\text {mean (rating) }}-V_{\text {mean (modell) }}$. 


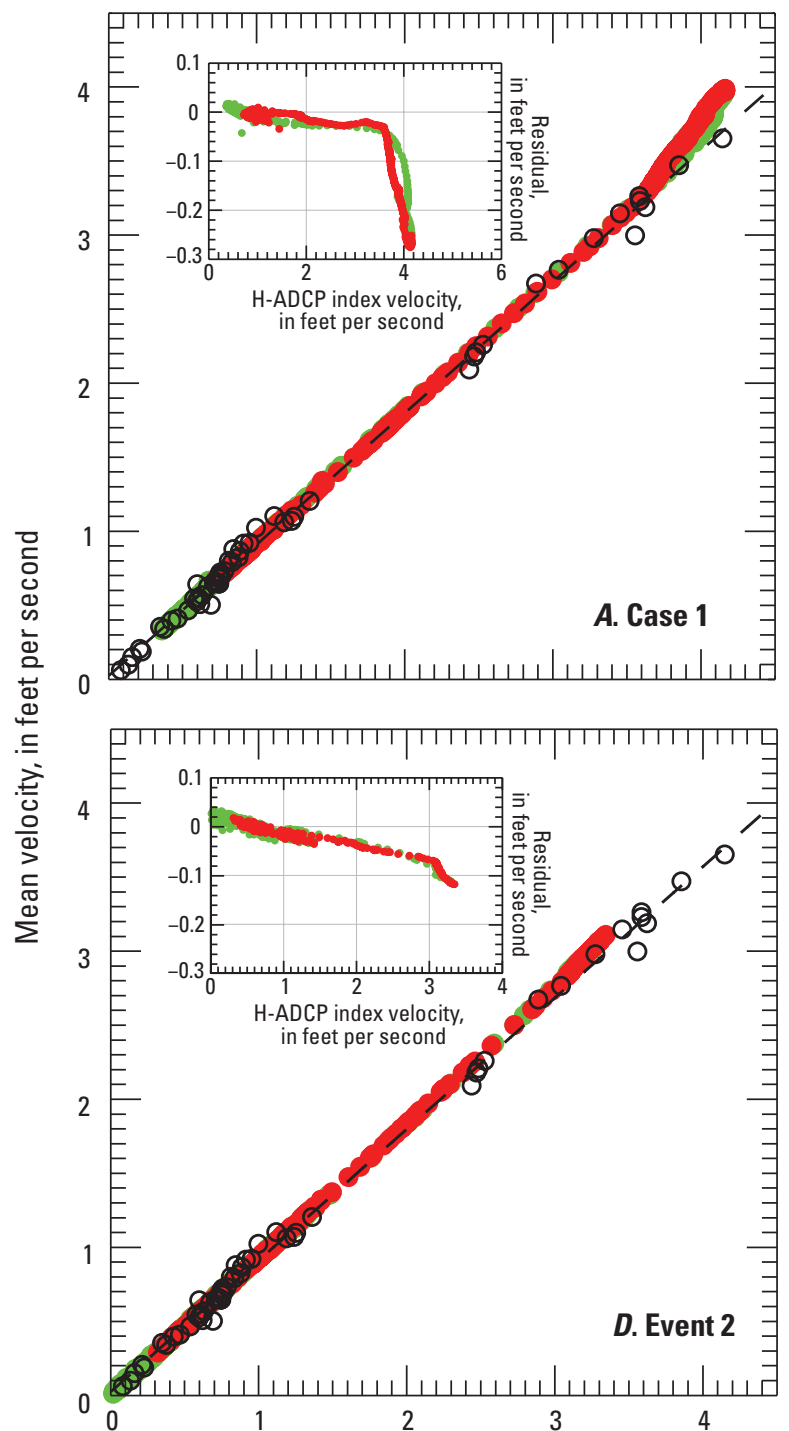

\section{EXPLANATION}

- - Field-derived rating (Jackson and others, 2012)

$0 \quad$ Field measurement (Jackson and others, 2012)

- Model rating point (rising limb)

- Model rating point (falling limb)
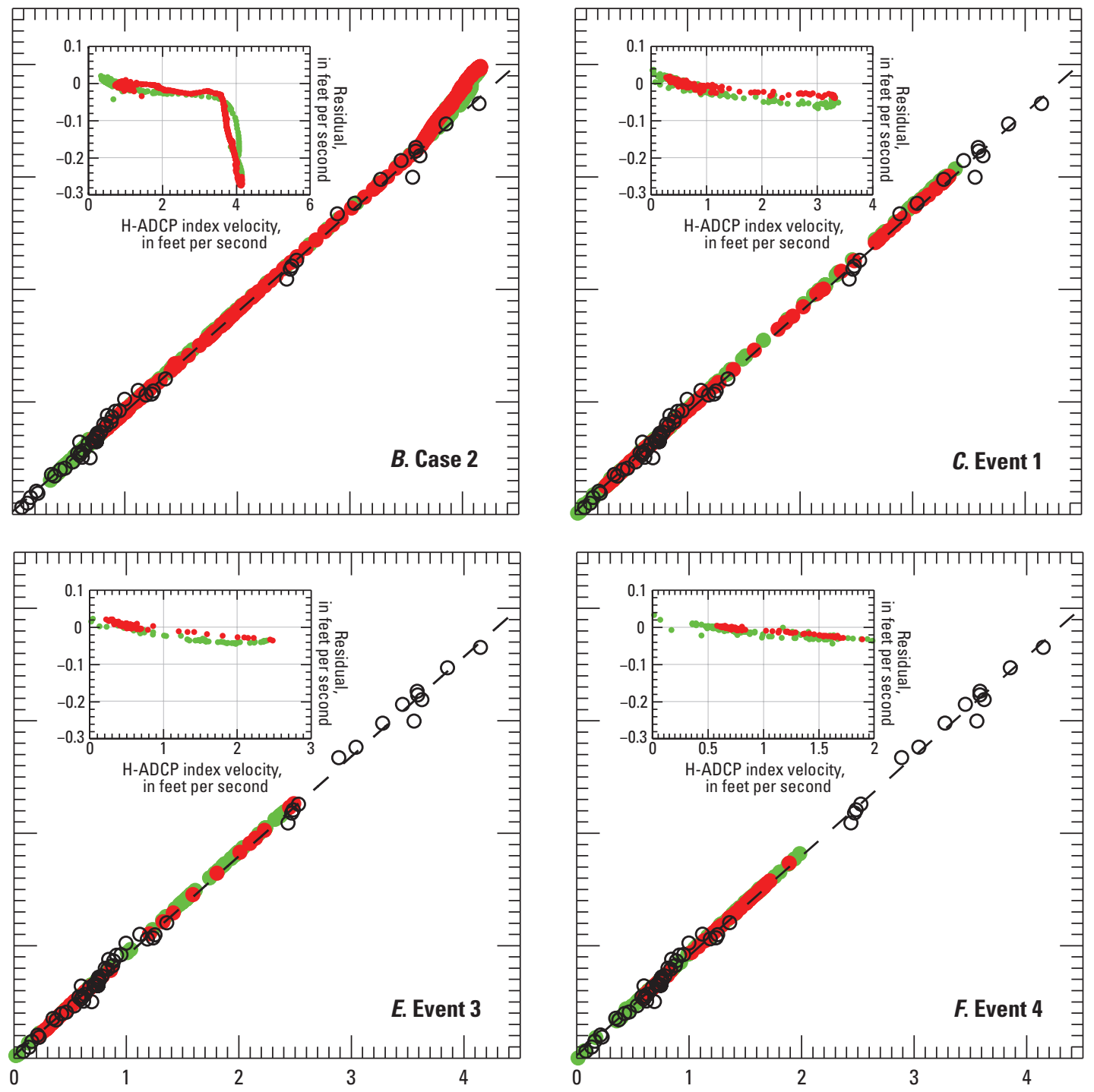

$\mathrm{H}-\mathrm{ADCP}$ index velocity, in feet per second

Figure 21. Model-derived index-velocity rating curves corresponding to the horizontal acoustic Doppler current profiler (H-ADCP) sensor configuration for all simulated cases and events. The fieldderived index-velocity rating for the H-ADCP is shown for reference, along with residuals comparing the model and field rating curves (residual $=V_{\text {mean (rating) }}-V_{\text {mean (model)) }}$. 
of the root mean squared error (RMSE) of the predicted velocities along the H-ADCP path was up to 3 times higher during the directly proportional stage-discharge period compared to the inversely proportional stage-discharge period (table 3 ). On average, the model underpredicted velocity magnitude in the H-ADCP section, and the underprediction significantly increases when the stage-discharge relation becomes directly proportional. The magnitude of this underprediction during the peak of the event for case 1 and case $2($ median $=0.56 \mathrm{ft} / \mathrm{s}$ ) is more than enough to account for the deviation of the model rating from the field rating at the highest velocities (deviation $\approx 0.33 \mathrm{ft} / \mathrm{s}$ ).

The underprediction of velocity magnitude in the measurement cross section can be attributed to the inability of the model to accurately capture the stage and discharge during the peak of the events for case 1, case 2, and event 2 (figs. 18 and 19). Modeled discharges for case 1 and case 2 are underestimated by as much as $2,000 \mathrm{ft}^{3} / \mathrm{s}$ on the rising limb near the peak of the event (fig. 19); and although the discharge on the falling limb is much closer to the observed discharge (slightly higher), the modeled stage on the falling limb is overpredicted (fig. 18). Both a low discharge and a high stage (high cross-sectional area) lead to lower velocities in the section. The inability of the model to accurately capture the peak of these flows will affect both the index velocity, $V_{\text {indx }}$, and the mean velocity, $V_{\text {mean }}$, and it appears to change the relation between the two velocities enough to cause a change in the slope of the index-velocity rating. In addition, because the change is induced by a low-biased discharge on the rising limb and a high-biased stage on the falling limb, the slope of the upper part of the rating curve for these events varies, causing slight hysteresis. This hysteresis, however, and the overall deviation in the linear trend of the rating curve at high flows for case 1 and case 2 (also for event 2) appear to be entirely due to inaccuracies of the model and are not supported by field measurements, which do not show any break in the linear ratings (figs. 20 and 21).

Table 3. Error between predicted and observed velocities in the nine cells of the horizontal acoustic Doppler current profiler in the Chicago Sanitary and Ship Canal near Lemont, Illinois. Median values of the root mean squared error (RMSE) are reported independently for the two stage-discharge relation regimes.

[ft/s, feet per second; --, not computed; n/a, not applicable]

\begin{tabular}{lcc}
\hline \multirow{2}{*}{ Case/Event } & \multicolumn{2}{c}{ Velocity RMSE, in ft/s } \\
\cline { 2 - 3 } & $\begin{array}{c}\text { Inversely proportional } \\
\text { stage-discharge relation }\end{array}$ & $\begin{array}{c}\text { Directly proportional } \\
\text { stage-discharge relation }\end{array}$ \\
\hline Case 1 & 0.18 & 0.56 \\
Case 2 & -- & -- \\
Event 1 & 0.17 & $\mathrm{n} / \mathrm{a}$ \\
Event 2 & 0.16 & 0.29 \\
Event 3 & 0.16 & $\mathrm{n} / \mathrm{a}$ \\
Event 4 & 0.16 & $\mathrm{n} / \mathrm{a}$ \\
\hline
\end{tabular}

The cause of the uncertainty of the model during the directly proportional stage-discharge relation portion of the hydrograph (large event peaks) is not entirely clear, but may be related to the synthetic partitioning of the flow to generate the upstream boundary conditions for case 1 and case 2 combined with the choice of Romeoville as a downstream boundary condition. The control for this system is at the Lockport Powerhouse and Lockport Lock and Dam about 6 mi downstream of Romeoville. Although the water-surface elevation at Romeoville may be adequate as a downstream boundary condition for most flow conditions, it might be inadequate for the peaks of large events that display a directly proportional stage-discharge relation. Moving the downstream boundary condition to Lockport might result in better agreement over the full range of flows observed at Lemont, but doing so would require modeling of the complex reach between Romeoville and Lockport, which includes a powerplant with intakes and outfall, the Controlling Works with its seven sluice gates, and the Lockport Lock and Powerhouse (two turbines and sluice gates). Not only is this reach complicated to model and beyond the scope of this project, but much of the data required to properly model this reach is nonexistent.

\section{Conclusions}

The U.S. Geological Survey is responsible for monitoring flows in the Chicago Sanitary and Ship Canal (CSSC) near Lemont, Illinois (Ill.), as a part of the Lake Michigan Diversion Accounting overseen by the U.S. Army Corps of Engineers, Chicago District. Lake Michigan Diversion Accounting is mandated by a U.S. Supreme Court decree in order to monitor, and limit, the State of Illinois' annual diversion of Great Lakes' water through the manmade Chicago Sanitary and Ship Canal. Every 5 years, a technical review committee consisting of practicing engineers and academics reviews the U.S. Geological Survey's streamgaging practices in the CSSC near Lemont, Ill. The sixth technical review committee expressed concern that the index-velocity rating at this gage may be subject to hysteresis due to the unique, unsteady hydraulics of the canal. Hysteresis in index-velocity ratings can occur at sites where the flow distribution in the channel varies significantly between the rising and falling limbs of the hydrograph for the same discharge (Ruhl and Simpson, 2005). Presently, hysteresis in index-velocity ratings has been documented only at tidally affected sites.

This report investigates the possibility of hysteresis at this nontidal site and the conditions under which it would be likely to occur. Study methods involved both a theoretical approach and use of a three-dimensional hydrodynamic model. The theoretical analysis investigated the conditions required for hysteresis in the index-velocity rating, whereas the modeling analysis focused on the effect of the timing of the inflows from the CSSC and the Cal-Sag Channel on the potential for hysteresis and whether highly resolved simulations of actual high-flow events show any evidence of hysteresis. 
Theoretical analysis using a 13,200- $\mathrm{ft}^{3} / \mathrm{s}$ high-flow event hydrograph combined with theoretical transverse flow distributions in the CSSC near Lemont, Ill., showed that hysteresis in the index-velocity rating curve can be introduced by varying the transverse flow distribution in the measurement section between the rising and falling limbs of the hydrograph. Sensitivity analysis shows that hysteresis is most pronounced when the transverse flow distribution is peaked and skewed to one bank rather than symmetric in the cross section and when the distribution varies greatly between rising and falling limbs of the hydrograph. Although the theoretical analysis shows hysteresis can exist for the horizontal acoustic Doppler current profiler (H-ADCP) in the CSSC near Lemont and other configurations with unmeasured zones in the cross section, this theory does not produce hysteresis for the acoustic velocity meter (AVM), which samples the full cross section. And, although theory allows for the possibility of hysteresis, the observed transverse velocity profiles in the CSSC near Lemont do not exhibit the spatial variation over high-flow events required to generate hysteresis for either instrument configuration (H-ADCP or AVM).

A three-dimensional hydrodynamic model was used to simulate six high-flow events of varying peak discharge between 7,200 to $19,000 \mathrm{ft}^{3} / \mathrm{s}$. The predicted flow field in the CSSC near Lemont from the model was then sampled over the duration of each event in a manner that replicates the gaging practices in the field. Data extracted from the simulations were used to develop index-velocity rating curves for the H-ADCP and AVM for each event. Model-derived index-velocity ratings for all six of the simulated high-flow events are in close agreement with the field-derived index-velocity rating for the Lemont gage given by Jackson and others (2012). No significant hysteresis was observed in the model-derived indexvelocity ratings for any of the six simulated high-flow events. Slight deviation from the field rating and small hysteresis in synthetic case 1 and case 2 at high flows can be attributed to the inability of the model to accurately replicate the discharge and stage in the CSSC near Lemont during the peak of the event and the associated underprediction of velocity magnitudes for the highest flows. This limitation of the model is likely due to a combination of synthetic flow partitioning used to define the upstream boundary conditions (given a lack of field observations for these cases) and the inability of the downstream boundary condition at Romeoville to fully capture the effect of the control at Lockport at peak flows. For synthetic case 1 and case 2, the ratings appeared to be insensitive to the timing of the discharge from the Cal-Sag Channel relative to the flow in the CSSC. The scatter in the rating points derived from field measurements is significantly larger than any observed hysteresis in the model and therefore is likely not an artifact of hysteresis in the field measurements.
Based on both the theoretical analysis using observed historical data and the analysis using a three-dimensional hydrodynamic model, there is no definitive evidence for the existence of hysteresis in the index-velocity rating at the USGS streamgage on the CSSC near Lemont, Ill. Whereas the theoretical analysis allowed for the possibility of hysteresis, the hydrodynamic conditions required to generate hysteresis do not appear to be present at this site, based on historical data. Though the hydrodynamic model shows some limitations at peak flows, leading to some uncertainty in the model results, we can conclude that any hysteresis in the index-velocity rating at this site, if it occurs, is small and likely to be well within the range of uncertainty due to other sources in field measurements of discharge and index-velocity used to develop the rating. Ongoing streamgaging practices at this site will rely on the information in this report and include periodic assessment of the index-velocity rating for any signs of hysteresis that might result from future changes to the operation of this manmade canal.

\section{References Cited}

Electricité de France, EDF-DER, 2007, Telemac Modelling System, 3-D Hydrodynamics TELEMAC-3D Code, release 5.8 operating manual, accessed March 28, 2013, at www.opentelemac.org.

Fread, D.L., 1975, Computations of stage-discharge relationships affected by unsteady flow: Water Resources Bulletin, v. 11, p. 213-218.

Hervouet, J.M., 2007, Hydrodynamics of free surface flowsModelling with the finite element method: Hoboken, N.J., John Wiley \& Sons, 341 p., ISBN: 978-0-470-03558-0.

Jackson, P.R., Johnson, K.K., and Duncker, J.J., 2012, Comparison of index velocity measurements made with a horizontal acoustic Doppler current profiler and a three-path acoustic velocity meter for computation of discharge in the Chicago Sanitary and Ship Canal near Lemont, Illinois: U.S. Geological Survey Scientific Investigations Report 2011-5205, 42 p.

Johnson, K.K., Duncker, J.J., and Jackson, P.R., 2012, The role of the U.S. Geological Survey in Lake Michigan Diversion Accounting in Illinois, 1984-2010: U.S. Geological Survey Open-File Report 2012-1243, 73 p.

Mander, R.J., 1978, Aspects of unsteady flow and variable backwater, in Herschy, R.W., ed., Hydrometry—Principles and practice (1st ed.): Chichester, UK, John Wiley \& Sons, p. 205-246. 
Prandtl, L., 1926, Über die ausgebildete Turbulenz, in Proceedings of the Second International Congress on Applied Mechanics, Zurich, Switzerland: p. 62-75.

Ruhl, C.A., and Simpson, M.R., 2005, Computation of discharge using the index-velocity method in tidally affected areas: U.S. Geological Survey Scientific Investigations Report 2005-5004, 31 p.
Seo, I.W., and Baek, K.O., 2004, Estimation of the longitudinal dispersion coefficient using the velocity profile in natural streams: Journal of Hydraulic Engineering, v. 130, no. 3, p. 227-236.

Wilcox, D.C., 2004, Turbulence modeling for CFD ( $2 \mathrm{~d}$ ed.): La Cañada, Calif., DCW Industries, Inc., 540 p., ISBN 1-928729-10-X. 

